\title{
CAMA
}

Centre for Applied Macroeconomic Analysis

\section{Identification robust empirical evidence on the Euler equation in open economies}

\section{CAMA Working Paper 7/2020 February 2020}

\section{Qazi Haque}

The University of Western Australia

Centre for Applied Macroeconomic Analysis, ANU

\section{Leandro M. Magnusson}

The University of Western Australia

\section{Abstract}

We investigate the empirical evidence on the Euler equation models using methods that are robust to weak instruments and structural changes for a set of eight countries. We start with the conventional closed economy model and consider extensions that include habits and hand-to-mouth consumers. We then extend the analysis to allow for each country to behave like an open economy. We find that structural changes are informative for the identification of the Euler equation models in some countries. However, in all countries, there is limited responsiveness of output to changes in the interest rate and no evidence of parameter instability, but otherwise aggregate data provide limited information to learn about Euler equation models. 


\section{Keywords}

Euler equation, Weak identification, Open economy

\section{JEL Classification}

$\mathrm{C} 1, \mathrm{C} 2, \mathrm{E} 1, \mathrm{~F} 4$

Address for correspondence:

(E) cama.admin@anu.edu.au

ISSN 2206-0332

The Centre for Applied Macroeconomic Analysis in the Crawford School of Public Policy has been established to build strong links between professional macroeconomists. It provides a forum for quality macroeconomic research and discussion of policy issues between academia, government and the private sector.

The Crawford School of Public Policy is the Australian National University's public policy school, serving and influencing Australia, Asia and the Pacific through advanced policy research, graduate and executive education, and policy impact. 


\title{
Identification robust empirical evidence on the Euler equation in open economies*
}

\author{
Qazi Haque $^{\dagger}$ and Leandro M. Magnusson ${ }^{\ddagger}$
}

January 30, 2020

\begin{abstract}
We investigate the empirical evidence on the Euler equation models using methods that are robust to weak instruments and structural changes for a set of eight countries. We start with the conventional closed economy model and consider extensions that include habits and hand-to-mouth consumers. We then extend the analysis to allow for each country to behave like an open economy. We find that structural changes are informative for the identification of the Euler equation models in some countries. However, in all countries, there is limited responsiveness of output to changes in the interest rate and no evidence of parameter instability, but otherwise aggregate data provide limited information to learn about Euler equation models.
\end{abstract}

Keywords: Euler equation; Weak identification; Open economy.

JEL Classification: $\mathrm{C} 1, \mathrm{C} 2, \mathrm{E} 1, \mathrm{~F} 4$.

\footnotetext{
${ }^{*}$ We would like to thank Fabio Canova, Efrem Castelnuovo, Tim Robinson, Yong Song, Francesco Zanetti and seminar participants at The University of Melbourne for very helpful discussions. The authors acknowledge generous support from the Australian Research Council under the grant DP170100697.

${ }^{\dagger}$ Postdoctoral Researcher, Economics Department, 35 Stirling Highway M251, Business School, The University of Western Australia, Crawley, WA 6009, Australia and Centre for Applied Macroeconomic Analysis, ANU; Email: qazi.haque@uwa.edu.au

${ }^{\ddagger}$ Corresponding author, Senior Lecturer, Economics Department, 35 Stirling Highway M251, Business School, The University of Western Australia, Crawley, WA 6009, Australia; Email: leandro.magnusson@uwa.edu.au.
} 


\section{Introduction}

The New Keynesian framework has become a workhorse model for the analysis of monetary policy. ${ }^{1}$ The model essentially reduces the economy to three major elements: a central bank that seeks to stabilize the output gap and to keep inflation as close to a target level as possible, a Phillips curve that expresses how a deviation of output from its potential level drives inflation dynamics, and an IS curve that represents the intertemporal Euler equation. The IS curve posits an inverse relationship between output and the real interest rate. Therefore, it provides an important channel for monetary policy to influence aggregate demand: consumers are assumed to substitute toward spending more when monetary policy lowers interest rates, and toward saving more when monetary policy brings interest rates up. The magnitude and direction of this effect is captured by the elasticity of intertemporal substitution (EIS), which is "a parameter of central importance in macroeconomics and finance", see Yogo (2004).

The literature on the IS curve has led to inconsistency between the values of the EIS that we expect from economic theory and its empirical estimates, giving rise to the so-called "IS puzzle". The EIS is often estimated to be not significantly different from zero (see, for example, Hall, 1988; Campbell and Mankiw, 1989; Paradiso et al., 2013), and when it is found to be significant, the EIS is often estimated to be small (or even negative, see Patterson and Pesaran, 1992; Goodhart and Hofmann, 2003; Gomes and Paz, 2013), suggesting that consumers are extremely risk averse. Havránek (2015) conducted a meta-analysis on 169 published studies and concluded that the average estimate of the EIS in aggregate data is zero, once corrected for publication bias. ${ }^{2}$ Two major causes of the IS puzzle suggested in the literature are: first, that the problem is purely an econometric one, arising from weak identification or time variance in the structural parameters in the model (Stock et al., 2002); and second, that the IS curve is misspecified and cannot be fitted to empirical data (Stracca, 2010).

In this paper, we address both potential causes of the IS puzzle. First, we test the traditional "baseline" specification of the IS curve using methods proposed by Stock and Wright (2000) and Magnusson and Mavroeidis (2014) that are robust to weak identification and structural changes. The methods of Magnusson and Mavroeidis (2014) can also be interpreted as parameter stability tests robust to weak instruments and therefore can provide evidence on structural breaks in the IS curve. Second, we investigate several extensions of the baseline Euler equation model to include (i) habit formation in consumption as in Dennis (2009), (ii) hand-to-mouth consumers (HTMC) as in Bilbiie and Straub (2012), (iii) open economy (OE) framework as in Clarida et al. (2002) and Galí and Monacelli (2005), and finally (iv) extensions of the IS curve that

1 See Goodfriend and King (1997), Clarida et al. (1999), Woodford (2003), and Galí (2008) for exposition of the New Keynesian model.

2 For studies estimating EIS using micro data, Havránek (2015) finds the EIS to be also very low and is around 0.3-0.4. 
separately incorporate consumption habits and HTMC into a OE model. We test these specifications using a set of eight countries fitting the features of open economies: Australia, Canada, Denmark, Norway, New Zealand, Sweden, Switzerland and the United Kingdom. Most existing studies investigating the IS puzzle focus on the United States, and hence our empirical contribution helps to fill this gap.

A common proposal for respecifying the IS curve is to introduce backward-looking dynamics, as the conventional model is purely forward-looking. Habit formation in consumption is a standard mechanism to achieve this as it generates inertia in consumption dynamics, thereby lowering the responsiveness of consumption to interest rate changes. Habits in consumption are now a standard feature in macroeconomic DSGE models. ${ }^{3}$ Another mechanism to lower the aggregate EIS in the Euler equation is to introduce hand-to-mouth consumers, e.g. see Campbell and Mankiw (1989), Bilbiie (2008) and Bilbiie and Straub (2012). HTMC do not have access to financial markets and simply consume their income. Finally, the models are extended to incorporate an external sector for both theoretical and empirical reasons. On the theoretical side, the assumption of an open economy is perhaps more realistic for the set of countries we consider. On the empirical side, open economy features can potentially improve identification of the parameters by exploiting stability restrictions in subsamples as proposed by Magnusson and Mavroeidis (2014). Our findings read as follows.

First, the baseline closed economy Euler equation model results in small values of the EIS, with values estimated to be lower than 1 in most countries. The exceptions are Canada and Switzerland, where we find evidence of structural breaks in the baseline IS curve.

Second, extending the baseline closed economy model to allow for habits, we find that higher degree of habits permits higher values of the EIS. However, this comes at a cost since the degree of habits is completely unindentified, suggesting that instruments are weak. Likewise, in models with HTMC, the fraction of HTMC is not well identified in most countries, except Sweden and Switzerland. As with habits, higher fraction of HTMC permits higher values of the EIS at the cost of estimation uncertainty. In Sweden and Switzerland, the fraction of HTMC is well identified and low, and so the EIS is also very low and not very different from the baseline model.

Third, the proposed extensions to incorporate features of an open economy are no more plausible than their closed economy counterparts. The degree of openness is completely unidentified in all countries using the methods of Stock and Wright (2000), except Denmark where it turns out to be low. However, exploiting the information on sub-sample instability provides better identification in three out of the eight countries in our dataset, namely Canada, Sweden and Switzerland. In contrast, sub-sample information does not provide additional identification for the other countries. Nevertheless, the EIS is lower than 1 in most countries,

\footnotetext{
3 See Christiano et al. (2005) and Smets and Wouters (2007).
} 
except for models with habits where higher degree of habits admits higher values of the EIS, but at the cost of identification of the habit parameter. Moreoever, as with the closed economy model, the fraction of HTMC remains poorly identified in most countries and higher fraction of HTMC allows for higher values of the EIS, again at the cost of estimation uncertainty. ${ }^{4}$

Fourth, we cannot reject the hypothesis that the structural parameters are stable over the entire sample. In particular, changes in the EIS, arising possibly from financial liberalization as agued by Bilbiie and Straub (2012) for the case of the United States, are not detected in the countries in our dataset.

Fifth, aggregate macro data are not sufficiently informative to study Euler equation models and its various extensions considered in this paper.

The paper closest to ours is Ascari et al. (2019). They apply the methods of Stock and Wright (2000) and Magnusson and Mavroeidis (2014) to study the empirical evidence on the Euler equation using aggregate post-war US data and consider similar extensions that include habits and HTMC in closed economy models. They find that $(i)$ the slope of the Euler equation is well identified and not significantly different from zero, (ii) there is no evidence of parameter instability, (iii) structural change is not informative for the identification of the Euler equation, and $(i v)$ aggregate data provide little information to distinguish between alternative models. On the theoretical side, we depart from Ascari et al. (2019) by extending the set of models to include an external sector and by deriving variants of the Euler equation models for an open economy. On the empirical side, we apply the same econometric methods that are robust to weak instruments and potential instability to study the empirical evidence on the Euler equation for a set of eight countries. First, with respect to $(i)$ and $(i i)$, for all countries in our dataset, we also find limited responsiveness of output to changes in the real interest rate and no evidence of parameter instability, respectively. With respect to (iii), we find that structural changes are informative for the identification of the Euler equation models for Canada, Sweden and Switzerland. This finding implies that structural changes in these open economies help to improve identification of parameters using stability restrictions. Finally, similar to (iv), we find aggregate data to be insufficiently informative to learn about Euler equation models. Our contributions may be seen as complementary to Ascari et al. (2019).

The paper is organized as follows. The next section describes the different Euler equation models including extensions to open economy. Section 3 describes the econometric methodology and the dataset. Section 4 presents the empirical results while Section 5 concludes.

\footnotetext{
4 The exceptions are Sweden and Switzerland, where, as discussed above, the fraction of HTMC is low and EIS is not significantly different from zero.
} 


\section{Euler Equation Models for Closed and Open Economies}

We consider first the closed economy baseline Euler equation model and two of its extensions: one with habit formation and another with hand-to-mouth consumers. We further consider extension of these models to include the external sector. This extension allows the countries to behave like open economies. An overview of each model is given in the subsections below.

\section{The closed economy baseline Euler equation}

The representative household maximizes a standard intertemporal utility function of the form

$$
\mathbb{E}_{t}\left[\sum_{i=0}^{\infty} \beta^{i} u\left(C_{t+i}\right)\right],
$$

where $\beta$ is the subjective discount factor, which is set to $\beta=0.99$ in our empirical investigation, and $C_{t+i}$ is consumption in period $t+i$. We use the shorthand notation $\mathbb{E}_{t}[\cdot]=\mathbb{E}\left[\cdot \mid \mathcal{I}_{t}\right]$, where $\mathcal{I}_{t}$ is the set of information available to the consumer in period $t$. The instantaneous utility function, $u$, exhibits constant relative risk aversion (CRRA), i.e.

$$
u\left(C_{t}\right)=\frac{C_{t+i}^{1-\frac{1}{\sigma}}}{1-\frac{1}{\sigma}},
$$

where $\sigma$ is the elasticity of intertemporal substitution (EIS) or the inverse of the degree of risk aversion. The first order condition for the household's optimal consumption reads

$$
\frac{1}{1+i_{t}}=\mathbb{E}_{t}\left[\beta \frac{u_{c}\left(C_{t+1}\right)}{u_{c}\left(C_{t}\right)} \frac{P_{t}}{P_{t+1}}\right],
$$

where $i_{t}$ is the nominal yield on a one-period risk-free bond and $u_{c}$ is the marginal utility of consumption.

Log-linearizing the above expression yields the baseline Euler equation:

$$
\hat{c}_{t}=\mathbb{E}_{t} \hat{c}_{t+1}-\sigma \hat{r}_{t}
$$

where $\hat{c}_{t}$ denotes the log-deviation of consumption from steady state, and $\hat{r}_{t}=\hat{i}_{t}-\mathbb{E}_{t} \hat{\pi}_{t+1}$ denotes the log-deviation of the ex-ante real interest rate from the steady state. Henceforth, all variables with a hat denote log-deviations from steady state.

The standard Euler equation depicts a negative reaction of consumption to the real interest rate due to intertemporal substitution and is crucial for the transmission mechanism of monetary policy in New Keynesian models. Nevertheless, several studies have pointed out that the baseline Euler equation model does not fit the aggregate data well. In particular, aggregate consumption appears unresponsive to the real interest rate, 
i.e. the estimated EIS is very low for the baseline Euler equation model. However, in the specification of the intertemporal utility maximization problem faced by the representative consumer, $\sigma$ is also the inverse of the coefficient of relative risk aversion in consumption. The implication of finding $\sigma \approx 0$ is that the representative consumer is near-infinitely risk averse, a conclusion that seems to be at odds with reality.

\section{Closed economy with Habits}

Fuhrer and Rudebusch (2004) and Paradiso et al. (2013), among others, empirically question the purely forward-looking nature of the IS curve, and introduce backward-looking dynamics into the model. This introduction is justified, for example, by allowing consumption habits: consumers consider past consumption choices when making current-period decisions. As argued by Fuhrer (2000), permitting habit formation makes the IS curve a more realistic approximation of the relationship between consumption, interest rates, and inflation. Following Fuhrer and Rudebusch (2004) and Dennis (2009), we assume additive habits, so the utility function takes the following form:

$$
u\left(C_{t}, H_{t}\right)=\frac{\left(C_{t}-H_{t}\right)^{1-\frac{1}{\sigma}}}{1-\frac{1}{\sigma}},
$$

and the stock of habits evolve as:

$$
H_{t}=\gamma\left(C_{t-1}^{D} \tilde{C}_{t-1}^{1-D}\right)
$$

where $\tilde{C}_{t}$ denotes aggregate consumption. The parameter $\gamma \in[0,1]$ measures the degree of dependence on habits; if $\gamma=0$ habits play no role and the model collapses to the baseline case, and if $\gamma=1$ consumption is perfectly predetermined. The parameter $D \in\{0,1\}$ is a dummy that determines the nature of the habits. If $D=0$ habits are external, i.e. the consumer is concerned with the level of her current consumption relative to the aggregate consumption in the previous period. If $D=1$ then the consumer is concerned with the level of her current consumption relative to her consumption in the previous period.

Following Dennis (2009), the log-linearized Euler equation in the case of external habits can be written as

$$
\mathbb{E}_{t} \Delta \hat{c}_{t+1}=\gamma \Delta \hat{c}_{t}+\sigma(1-\gamma) \hat{r}_{t}
$$

As seen from the above equation, habits modify the baseline model by introducing a lagged term $\Delta \hat{c}_{t}$, thereby changing the relative degree of backward-lookingness and forward-lookingness of the Euler equation. Moreover, external habits introduce a wedge between individual EIS, i.e. $\sigma$, and the aggregate one. The case for internal 
habits includes additional forward-looking components:

$$
\mathbb{E}_{t} \Delta \hat{c}_{t+1}=\frac{\gamma}{\left(1+\gamma^{2} \beta\right)}\left(\Delta \hat{c}_{t}+\beta \mathbb{E}_{t} \Delta \hat{c}_{t+2}\right)+\sigma \frac{(1-\gamma)(1-\gamma \beta)}{\left(1+\gamma^{2} \beta\right)} \hat{r}_{t}
$$

Importantly, when $\gamma=0$, both cases collapse back to the baseline equation.

\section{Hand-to-mouth consumers}

The assumption underlying the baseline Euler equation model is that all agents in the economy optimize their expected lifetime utility by substituting present consumption for saving, and vice-versa. We relax this assumption by allowing for a certain proportion of the population that have no assets and simply consume their entire labour income in any given period, hereafter called hand-to-mouth consumers (HTMC). Following Bilbiie and Straub (2012) we let $\tilde{\lambda}$ be the proportion of HTMC in the economy, where $\tilde{\lambda} \in[0,1]$. Hence, aggregare consumption is split between Ricardian (optimizing) households with access to saving $(R)$ and non-Ricardian HTMC with no such access $(N)$ as follows:

$$
C_{t}=(1-\tilde{\lambda}) C_{t}^{R}+\tilde{\lambda} C_{t}^{N}
$$

Log-linearizing this expression yields $\hat{c}_{t}=(1-\lambda) \hat{c}_{t}^{R}+\lambda \hat{c}_{t}^{N}$ where $\lambda \equiv \tilde{\lambda} C^{N} / C$ is the fraction of total consumption consumed by HTMC in the steady state. The baseline Euler equation (2.2) applies to Ricardian households only:

$$
\hat{c}_{t}^{R}=\mathbb{E}_{t} \hat{c}_{t+1}^{R}-\sigma \hat{r}_{t}
$$

Substituting $\hat{c}_{t}^{R}=\frac{\hat{c}_{t}-\lambda \hat{c}_{t}^{N}}{1-\lambda}$ gives an Euler equation with HTMC:

$$
\mathbb{E}_{t} \Delta \hat{c}_{t+1}=\lambda \mathbb{E}_{t} \Delta \hat{c}_{t+1}^{N}+(1-\lambda) \sigma \hat{r}_{t}
$$

Following Campbell and Mankiw (1989), we assume that a constant fraction of total labor income goes to HTMC. Hence, since consumption and income are in log-deviations, it follows that we can replace $\Delta \hat{c}_{t}^{N}$ with the change in aggregate labor income, thereby obtaining equations containing only observable aggregate variables. Finally, note that the assumption of HTMC modifies the aggregate EIS, which is reduced in proportion to the share of HTMC, i.e. aggregate EIS is given by $(1-\lambda) \sigma$ in $(2.6)$ while individual EIS is still given by $\sigma$. 


\section{Open economy extensions}

Clarida et al. (2002) and Galí and Monacelli (2005) study a class of DSGE models with nominal rigidities to analyze optimal monetary policy in open economies. Following these authors, we extend the baseline model to incorporate an external sector capturing trade with the rest of the world. As in Clarida et al. (2002), there are two countries, home and foreign, that differ in size but are otherwise symmetric. The home country $(H)$ has a mass of households $1-\omega$, and the foreign country $(F)$ has a mass $\omega$. Otherwise, preferences and technologies are the same across countries. Within each country, households consume a domestically produced good and an imported good. Households in both countries also have access to a complete set of Arrow-Debreu securities which can be traded both domestically and internationally. We next present the essential features of the model required to derive the Euler equation in an open economy.

Let $C_{t}$ be the following index of consumption of home $(\mathrm{H})$ and foreign $(\mathrm{F})$ goods:

$$
C_{t} \equiv\left[(1-\omega)^{\frac{1}{\eta}}\left(C_{H, t}\right)^{\frac{\eta-1}{\eta}}+\omega^{\frac{1}{\eta}}\left(C_{F, t}\right)^{\frac{\eta-1}{\eta}}\right]^{\frac{\eta}{\eta-1}},
$$

where $\eta>0$ measures the substitutability between domestic and foreign goods from the viewpoint of the domestic consumer. The parameter $\omega \in[0,1]$ is inversely related to the degree of home bias in preferences, and so can also be interpreted as a degree of openness. Let $P_{t}$ be the corresponding consumption price index (that follows from cost minimization):

$$
P_{t} \equiv\left[(1-\omega)\left(P_{H, t}\right)^{1-\eta}+\omega\left(P_{F, t}\right)^{1-\eta}\right]^{\frac{1}{1-\eta}},
$$

which when log-linearized around a symmetric steady state satisfying the purchasing power parity (PPP) condition $P_{H, t}=P_{F, t}$ yields

$$
\begin{aligned}
p_{t} & \equiv(1-\omega) p_{H, t}+\omega p_{F, t} \\
& =p_{H, t}+\omega \hat{s}_{t},
\end{aligned}
$$

where lower case letters denote the logs of the respective variables (with $p_{t} \equiv \log P_{t}$ ) and $\hat{s}_{t} \equiv p_{F, t}-p_{H, t}$ denotes the $(\log )$ terms of trade, i.e. the price of foreign goods in terms of home goods. ${ }^{5}$

Then the representative household in the home country maximizes

$$
\mathbb{E}_{t}\left[\sum_{i=0}^{\infty} \beta^{i} u\left(C_{t+i}\right)\right]
$$

\footnotetext{
5 Since $P_{F}=P_{H}$ (in a symmetric steady state satisfying the PPP condition), the (log) terms of trade in steady state is zero and so $s_{t} \equiv \hat{s}_{t}$.
} 
and the instantaneous utility function exhibits CRRA as before. The first-order necessary conditions for consumption allocation and intertemporal optimization are standard:

$$
\begin{aligned}
C_{H, t} & =(1-\omega)\left(\frac{P_{H, t}}{P_{t}}\right)^{-\eta} C_{t}, \\
C_{F, t} & =\omega\left(\frac{P_{F, t}}{P_{t}}\right)^{-\eta} C_{t}, \\
Q_{t, t+1} & =\beta \mathbb{E}_{t}\left[\left(\frac{C_{t+1}}{C_{t}}\right)^{-\sigma} \frac{P_{t}}{P_{t+1}}\right],
\end{aligned}
$$

where $Q_{t, t+1}=1 /\left(1+i_{t}\right)$ is the price of the risk-free bond.

A symmetric set of first-order conditions holds for citizens of the foreign country. In paricular, given the international tradability of state-contingent securities, the intertemporal optimality condition can be written as:

$$
Q_{t, t+1}=\beta \mathbb{E}_{t}\left[\left(\frac{C_{t+1}^{*}}{C_{t}^{*}}\right)^{-\sigma}\left(\frac{P_{t}^{*}}{P_{t+1}^{*}}\right)\left(\frac{E_{t}}{E_{t+1}}\right)\right] .
$$

The law of one price, which implies $P_{t}=E_{t} P_{t}^{*}$ for all $t$, where $E_{t}$ is the nominal exchange rate, in conjunction with (2.13) and (2.14), and a suitable normalization of initial conditions, yields:

$$
C_{t}=C_{t}^{*},
$$

for all $t$.

Goods market clearing in the home and foreign countries implies

$$
\begin{aligned}
(1-\omega) Y_{t} & =(1-\omega) C_{H, t}+\omega C_{H, t}^{*}, \\
\omega Y_{t}^{*} & =(1-\omega) C_{F, t}+\omega C_{F, t}^{*},
\end{aligned}
$$

where $Y_{t}$ and $Y_{t}^{*}$ denote aggregate output in home and foreign countries respectively.

The demand curves for home and foreign goods by home citizens, (2.11) and (2.12), respectively, along with the analogues for the foreign citizens and the law of one price imply that the CPI-based real exchange rate is unity. It then follows, after also taking into account (2.16) and (2.17), that

$$
\begin{aligned}
Y_{t} & =\left(\frac{P_{H, t}}{P_{t}}\right)^{-\eta} C_{t}, \\
Y_{t}^{*} & =\left(\frac{P_{H, t}^{*}}{P_{t}^{*}}\right)^{-\eta} C_{t}^{*},
\end{aligned}
$$


which when log-linearized around a symmetric steady state can be written as

$$
\begin{aligned}
& \hat{y}_{t}=\hat{c}_{t}-\eta p_{H, t}+\eta p_{t}, \\
& \hat{y}_{t}^{*}=\hat{c}_{t}^{*}-\eta p_{F, t}^{*}+\eta p_{t}^{*} .
\end{aligned}
$$

Finally, combining (2.9) and (2.20) provides an aggregate demand schedule that relates domestic per capita output, per capita consumption, and the terms of trade as follows:

$$
\hat{c}_{t}=\hat{y}_{t}-\eta \omega \hat{s}_{t} .
$$

Substituting this expression into the closed economy baseline Euler equation (2.2), gives an open-economy equivalent:

$$
\mathbb{E}_{t} \Delta \hat{y}_{t+1}=\sigma \hat{r}_{t}+\eta \omega \mathbb{E}_{t} \Delta s_{t+1}
$$

If $\omega=0$, i.e. when there are precisely zero imports in the domestic household's consumption bundle, then $\hat{c}_{t}=\hat{y}_{t}$ and this expression collapses to the baseline Euler equation (2.2).

\section{Habits in an open economy}

We extend the open economy Euler equation model by allowing for habit formation in consumption as before. The key result in the open economy extension is given in (2.22), as it provides an explicit relationship between the representative domestic consumer's allocation of their income and the effective terms of trade facing the domestic economy. This result is easily substituted into the external habit specification in (2.4), yielding:

$$
\mathbb{E}_{t} \Delta \hat{y}_{t+1}=\gamma \Delta \hat{y}_{t}+\sigma(1-\gamma) \hat{r}_{t}+\eta \omega\left[\mathbb{E}_{t} \Delta \hat{s}_{t+1}-\gamma \Delta \hat{s}_{t}\right] .
$$

Extending the external habit case to an open economy introduces backward- and forward-looking dependence on the effective terms of trade, implying that habitual consumers consider the relative prices of imports and domestic goods, as well as the ex-ante real interest rate, when making consumption decisions. Substituting (2.22) into the internal habit case in (2.5) yields:

$$
\begin{aligned}
\mathbb{E}_{t} \Delta \hat{y}_{t+1} & =\frac{\gamma}{\left(1+\gamma^{2} \beta\right)}\left[\Delta \hat{y}_{t}+\beta \mathbb{E}_{t} \Delta \hat{y}_{t+2}\right]+\sigma \frac{(1-\gamma)(1-\gamma \beta)}{\left(1+\gamma^{2} \beta\right)} \hat{r}_{t} \\
& +\eta \omega\left[\mathbb{E}_{t} \Delta \hat{s}_{t+1}-\frac{\gamma}{\left(1+\gamma^{2} \beta\right)}\left(\Delta \hat{s}_{t}+\beta \mathbb{E}_{t} \Delta \hat{s}_{t+2}\right)\right] .
\end{aligned}
$$


When the economy is closed $(\omega=0)$, these models collapse to their respective habit counterparts, (2.4) and (2.5) respectively, and when the consumer displays no habitual behaviour $(\gamma=0)$, these models collapse to the small open economy model in (2.23).

\section{HTMC in an open economy}

Finally, we extend the open economy Euler equation model by allowing for HTMC in the domestic economy. ${ }^{6}$ The set up of the model is similar to the baseline open economy described above. However, a share $(1-\tilde{\lambda})$ of the domestic households is Ricardian, where $\tilde{\lambda} \in[0,1]$ is the proportion of HTMC consumers in the domestic economy. Aggregate consumption in the domestic economy is split between Ricardian (R) and nonRicardian HTMC consumers (N) as before. The first-order necessary conditions for consumption allocation and intertemporal optimization for Ricardian households are:

$$
\begin{aligned}
C_{H, t}^{R} & =(1-\omega)\left(\frac{P_{H, t}}{P_{t}}\right)^{-\eta} C_{t}^{R}, \\
C_{F, t}^{R} & =\omega\left(\frac{P_{F, t}}{P_{t}}\right)^{-\eta} C_{t}^{R}, \\
Q_{t, t+1} & =\beta \mathbb{E}_{t}\left[\left(\frac{C_{t+1}^{R}}{C_{t}^{R}}\right)^{-\sigma} \frac{P_{t}}{P_{t+1}}\right],
\end{aligned}
$$

where the Euler equation (2.28) applies to Ricardian households only. Likewise, the first order conditions for consumption allocation for non-Ricardian households are:

$$
\begin{aligned}
C_{H, t}^{N} & =(1-\omega)\left(\frac{P_{H, t}}{P_{t}}\right)^{-\eta} C_{t}^{N}, \\
C_{F, t}^{N} & =\omega\left(\frac{P_{F, t}}{P_{t}}\right)^{-\eta} C_{t}^{N},
\end{aligned}
$$

Under the assumption of complete securities market, a first order condition analogous to (2.26)-(2.28) must hold for the representative household in the foreign country (where, following Boerma (2014), we assume there are no HTMC in the foreign economy). The law of one price together with the Euler equations for home (Ricardian) and foreign households yield:

$$
C_{t}^{R}=C_{t}^{*}
$$

for all $t$. Equation (2.31) implies that only Ricardian households share risk internationally. The non-Ricardian agents do not, because they do not have access to the securities that would enable them to do so.

${ }^{6}$ See Boerma (2014) for a small open econony version of the Calvo-type staggered price setting model with limited asset market participation. 
Goods market clearing in the home and foreign countries yields

$$
\begin{aligned}
(1-\omega) Y_{t} & =(1-\omega) \lambda C_{H, t}^{N}+(1-\omega)(1-\lambda) C_{H, t}^{R}+\omega C_{H, t}^{*} \\
\omega Y_{t}^{*} & =(1-\omega) \lambda C_{F, t}^{N}+(1-\omega)(1-\lambda) C_{F, t}^{R}+\omega C_{F, t}^{*}
\end{aligned}
$$

Combining the demand functions for home goods by Ricardian and non-Ricardian households, (2.26) and (2.29) respectively, together with the goods market clearing condition for home country, (2.32), and the law of one price, imply the following aggregate demand schedule

$$
Y_{t}=(1-\omega)\left(\frac{P_{H, t}}{P_{t}}\right)^{-\eta} C_{t}+\omega\left(\frac{P_{H, t}}{P_{t}}\right)^{\eta} C_{t}^{R}
$$

Log-linearizing the above condition around a symmetric steady state yields

$$
\hat{y}_{t}=(1-\omega) \hat{c}_{t}+\omega \hat{c}_{t}^{R}+\eta \omega \hat{s}_{t}
$$

where we have substituted $p_{t}-p_{H, t}=\omega \hat{s}_{t}$. The above equation can be rearranged as

$$
\hat{c}_{t}=\left(\frac{1}{1-\omega}\right) \hat{y}_{t}-\left(\frac{\omega}{1-\omega}\right) \hat{c}_{t}^{R}-\left(\frac{\eta \omega}{1-\omega}\right) \hat{s}_{t} .
$$

We can then use the equilibrium condition (2.36) to the apportionment of consumption between Ricardian and HTMC:

$$
\left(\frac{1}{1-\omega}\right) \hat{y}_{t}-\left(\frac{\omega}{1-\omega}\right) \hat{c}_{R, t}-\left(\frac{\eta \omega}{1-\omega}\right) \hat{s}_{t}=(1-\lambda) \hat{c}_{t}^{R}+\lambda \hat{c}_{t}^{N}
$$

Rearranging this expression in terms of $\hat{c}_{t}^{R}$ and substituting into the Euler equation for Ricardian households, i.e. the log-linearized version of (2.28), yields the Euler equation model for HTMC in an open economy:

$$
\mathbb{E}_{t} \Delta \hat{y}_{t+1}=\lambda(1-\omega) \mathbb{E}_{t} \Delta \hat{c}_{t+1}^{N}+[(1-\lambda)(1-\omega)+\omega] \sigma \hat{r}_{t}+\eta \omega \mathbb{E}_{t} \Delta \hat{s}_{t+1}
$$

As with the other open economy models, (2.37) collapses to its closed economy equivalent $(2.6)$ when $\omega=0$, i.e. when domestic agents do not consume any imports. Moreover, (2.37) collapses to the baseline open economy model in (2.23) when $\lambda=0$, i.e. when all agents are optimizers and there are no hand-to-mouth consumers. 


\section{Data and Methodology}

We use aggregate quarterly time series data for Australia, Canada, Denmark, Norway, New Zealand, Sweden, Switzerland, and the United Kingdom. ${ }^{7}$ We use logs of seasonally adjusted real gross domestic product for both $c_{t}$ and $y_{t}$, which implies that the Euler equation models are generalized to the whole aggregate demand and applied to aggregate output, as often done in small scale macro models.

The nominal interest rate $i_{t}$ is taken as a quarterly average of monthly observations of rates on 90-day treasury bills or a comparable 90-day interbank rate, which is in line with prevailing practice in the literature; this allows for a direct link to monetary policy. Inflation $\pi_{t}$ is computed as the log-difference between current and past-period levels of the consumer price index (CPI). The ex-post real interest rate $r_{t}$ is the difference between the nominal rate at time $t$ and the inflation rate at time $t+1$.

Given that hand-to-mouth households consume their entire income and do not save between periods, we utilise real total compensation of employees as a proxy for $C_{H, t}$, the consumption by HTMC, except for Sweden where we use real net disposable income. Log-deviations are used in the empirical analysis to make this substitution valid; clearly not all employee compensation are paid to HTMC, but assuming that a fixed proportion is, we can treat changes in employee compensation as a valid proxy for $\Delta \hat{c}_{H, t}$.

Finally, we use data for terms of trade, which is defined as the ratio of export to import price index.

Data were collected from a variety of sources including the FRED database and national statistical authorities; where this was not possible, gaps were filled using the International Monetary Fund's International Financial Statistics (IFS) database. The Appendix provides further details.

\section{$S$ and gen- $S$ tests}

We use the Generalized Method of Moments (GMM) framework proposed by Hansen and Singleton (1982), where unobserved expectations terms are replaced by their realizations, predetermined variables are used as instruments and orthogonality conditions are obtained by assuming that residuals are uncorrelated with variables that are pre-determined at time $t$. Considering the baseline Euler equation (2.2), we estimate the following specification:

$$
\Delta c_{t+1}=k+\sigma r_{t}+u_{t+1}
$$

where $k$ is a constant that captures steady state values of the real interest rate and consumption growth, $\Delta c_{t+1}=(1-L) c_{t+1}=\left(c_{t+1}-c_{t}\right), r_{t}=i_{t}-\pi_{t+1}$ is the ex-post real interest rate, and $u_{t+1}$ is a disturbance term. However, such Euler equation model is known to suffer from problems arising from weak instruments; see, for example, Yogo (2004) and Olea and Pflueger (2013). Therefore, we apply the $S$-test developed by Stock

\footnotetext{
$\overline{7}$ Details about the data set and the time periods used in the estimation are provided in the Appendix.
} 
and Wright (2000) to produce confidence sets that are robust to the potential presence of weak instruments. To make our estimation robust to the presence of unanticipated shocks, we only use predetermined variables as instruments as is standard in the literature. In particular, we assume the moment conditions satisfy $\mathbb{E}\left[Z_{t} u_{t+1}\right]=0$, where $Z_{t}$ is the set of instruments. The empirical moments of the linear models can be written as:

$$
\mathbb{E}\left[Z_{t}^{\prime}\left(\bar{Y}_{t} b(\theta)-d\right)\right]=0,
$$

or in matrix notation

$$
\mathbb{E}\left[Z^{\prime}(\bar{Y} b(\theta)-X d)\right]=0
$$

where $\bar{Y}_{t}$ are variables of the model, $X$ is a vector of ones, $b(\theta)$ is a vector which contains the structural parameters and d is strongly identified parameters, which are estimated before the computation of the statistical tests. All the models presented earlier can be casted in equation (3.3).

Testing the hypothesis that $\theta=\theta_{0}$ is equivalent to testing $b(\theta)=b_{0}$ against $b(\theta) \neq b_{0}$. The $S$-statistic for this test is then

$$
S\left(\theta_{0}\right)=\frac{1}{T}\left(\bar{Y} b_{0}-X \hat{d}\right)^{\prime} Z \widehat{V}\left(\theta_{0}, \hat{d}\right)^{-1} Z^{\prime}\left(\bar{Y} b_{0}-X \hat{d}\right)
$$

where $\widehat{V}\left(\theta_{0}, \hat{d}\right)$ is a heteroskedasticity and autocorrelation consistent (HAC) estimator of $\operatorname{Var}\left(T^{1 / 2} Z^{\prime}\left(\bar{Y} b_{0}-X \hat{d}\right)\right)$. The estimator for the untested parameter $d$ is obtained by minimizing a similar objective function under the null assumption:

$$
\hat{d}=\arg \min _{d} \frac{1}{T}\left(\bar{Y} b_{0}-X d\right) Z^{\prime} \widehat{V}\left(\theta_{0}, d\right)^{-1} Z^{\prime}\left(\bar{Y} b_{0}-X d\right)
$$

i.e., $\hat{d}$ is the continuously updated estimator (CUE) of Hansen et al. (1996). We use the Newey and West (1987) estimator with four lags and Bartlett kernel.

The $S$ test is sufficient for testing the validity of the population moment condition, however, it is not robust to potential instability in the moments or in the structural parameters. Magnusson and Mavroeidis (2014) propose an extension, the 'generalised $S$ ' (gen-S) tests, that examine whether the moment conditions are stable for a given $b_{0}$. The population moment condition in (3.3) can then be re-expressed as a set of two restrictions: a full-sample moment condition and a stability restriction. In general, these tests have the form:

$$
\text { gen- } S\left(\theta_{0}\right)=\operatorname{gen}-\tilde{S}\left(\theta_{0}, \tilde{m}\right)+\frac{\bar{m}}{1+\bar{m}} S\left(\theta_{0}\right) \text {, }
$$

where $\tilde{m} \geq 0$ and $\bar{m} \geq 0$ are weights attached to the violations of the stability (gen- $\tilde{S}$ ) and full-sample moment $(S)$ restrictions, respectively. Of the alternatives proposed, we choose the $q L L-S$ variant for this paper. 
Magnusson and Mavroeidis (2014) recommend it as being the most effective in several cases of instability, and it is the most powerful test in the presence of persistent time variation as described in Elliott and Müller (2006). This involves setting $\tilde{m}=\bar{m}=10$. The test is given by:

$$
\mathrm{qLL}-S\left(\theta_{0}\right)=\mathrm{qLL}-\tilde{S}\left(\theta_{0}\right)+\frac{10}{11} S\left(\theta_{0}\right)
$$

and rejects the hypothesis for large values of the statistic. The rejection of the hypothesis test indicates the presence of instability that can be induced, for example, by variations in the structural parameters over time or by time variations in other parts of the economy. As such, the qLL-S test can be interpreted as a structural change test that is robust to weak identification, so a non-rejection indicates parameter stability.

In overidentified models, the $S$ test also has power against misspecification, which makes it difficult to interpret small confidence sets, and is not asymptotically efficient under strong identification. To address these issues, we also compute the confidence sets using the extension of Kleibergen (2005) to GMM of the conditional likelihood ratio $(C L R)$ test of Moreira (2003). To conserve space, we report the $C L R$ confidence sets in the Appendix.

We invert the results of the $S, q L L-S$ and $C L R$ tests to produce the confidence sets. Let $\theta$ be the vector of structural parameters and $\Theta$ the parameter space. We test the null assumption $\theta=\theta_{0}$ against $\theta \neq \theta_{0}$ at the $10 \%$ significance level. The $90 \%$ confidence interval (set) is the collection of all $\theta \in \Theta$ for which the null assumption is not rejected. In the case of the baseline model, $\theta=\sigma$; for the open economy $\theta=(\sigma, \omega)$; for the habit models $\theta=(\sigma, \gamma)$; for the HTM model $\theta=(\sigma, \lambda)$; and in the case of the combined models $\theta=(\sigma, \gamma, \omega)$ or $(\sigma, \lambda, \omega)$. The parameters $\gamma, \omega$, and $\lambda$ are by nature restricted to the unit interval, i.e. $\gamma \in[0,1], \omega \in[0,1]$, and $\lambda \in[0,1]$, and as we are interested in realistic and applicable values of the elasticity of intertemporal substitution, we search within the space given by $\sigma \in[0,4]$. We set $\eta$, the parameter that governs substitutability between domestic and foreign goods, to 1 and report the robustness of our results to alternative calibrations of $\eta$ in the Appendix. We also calibrate $\beta$, the discount factor, to 0.99.

\section{Empirical Results}

We report $90 \%$ confidence sets on the structural parameters based on the S test of Stock and Wright (2000) and the $q L L-S$ test of Magnusson and Mavroeidis (2014) for Australia, Canada, Denmark, Norway, New Zealand, Sweden, Switzerland, and the United Kingdom in Figures 1 through 8 respectively. The set of instruments consists of a constant and the second lag of $\Delta y_{t},\left(i_{t-1}-\pi_{t}\right)$, and $\left(i_{t-1}^{*}-\pi_{t}^{*}\right)$, where $i_{t}^{*}$ is the U.S. Federal Funds Rate and $\pi_{t}^{*}$ is the U.S. GDP deflator inflation rate. For open economy models we also include 
the second lag of terms of trade growth $\Delta s_{t}$. Yogo (2004) shows that lagging the instruments twice assures that instruments are exogenous even if consumption or the real interest rate are conditionally heteroskedastic.

The upper panels in each figure report $S$ sets, while the lower panels report the corresponding $q L L-S$ sets. Panel $(a)$ in each figure reports the respective one-dimensional $90 \%$ confidence interval for $\sigma$ in the baseline closed economy model (2.2) if non-empty. Panels $(b)$ and $(c)$ report two-dimensional $90 \%$ confidence sets for $(\sigma, \gamma)$ in the closed economy model with external (2.4) and internal (2.5) habits, respectively. Panel $(d)$ reports two-dimensional $90 \%$ confidence sets for $(\sigma, \lambda)$ in the closed economy model with HTMC (2.6). Panel $(e)$ reports two-dimensional $90 \%$ confidence set for $(\sigma, \omega)$ in the baseline open economy model $(2.23)$. Panels $(f)$ and $(g)$ report three-dimensional $90 \%$ confidence sets for $(\sigma, \omega, \gamma)$ in the open economy model with external (2.24) and internal (2.25) habits, respectively. Finally, panel $(h)$ reports three-dimensional 90\% confidence set for $(\sigma, \omega, \lambda)$ in the open economy model with HTMC (2.37). Note that $\omega=0$ and $\gamma=0$ in panel $(f)$ correspond to the $90 \%$ confidence sets in panels $(b)$ and $(e)$ respectively, and similarly for $(g)$ with respect to $(c)$ and $(e)$. Likewise, $\omega=0$ and $\lambda=0$ in panel $(h)$ correspond to the $90 \%$ confidence sets in panels $(d)$ and $(e)$ respectively.

First, we discuss the results for each of the models in turn, starting from the baseline closed economy model. The $90 \% S$ and $q L L-S$ sets in panels $(a)$ and $(i)$, respectively, show that $\sigma$ is estimated to be lower than 1 in most of the countries. The exceptions are Canada and Switzerland where the $q L L-S$ sets are empty, suggesting there is no value of $\sigma \geq 0$ for which the identifying restrictions of the model are statistically acceptable at the $10 \%$ significance level. These results are mostly in line with the findings of Yogo (2004) and Ascari et al. (2019), who use same methods and show that the EIS is low for the standard specification of the Euler equation. This implies that monetary policy has little influence on aggregate output in the baseline model in these countries.

Turning to the model with habits (both external and internal) in panels $(b),(c),(j)$ and $(k)$, we can see that $\gamma$ is completely unidentified in most countries. Note that higher values of $\sigma$ become admissible as $\gamma$ increases in all countries, but this comes at a cost since $\gamma$ is left unidentified. In fact, the $90 \%$ confidence sets include $\gamma=1$, at which point $\sigma$ also becomes completely unidentified, i.e. if $\gamma=1$, then aggregate output will not respond at all to changes in the real interest rate at any level of $\sigma$. This implies that instruments are weak for future output growth. In addition, models with external and internal habits are empirically indistinguishable: they both fit the data but cannot be separately identified.

Next, considering the results for the model with HTMC in panels $(d)$ and $(l)$, we find that the fraction of HTMC $\lambda$ remains unidentified in all countries, except for Sweden and Switzerland. In all six countries where $\lambda$ is not properly identified, $\sigma$ increases with $\lambda$ and, with the exception of Canada, the confidence sets span the entire parameter space for $\lambda$. As with habits, $\sigma$ becomes completely unidentified when $\lambda=1$, meaning 
that if all consumers are HTMC, then aggregate consumption will not respond at all to the real interest rate at any level of $\sigma$. However, the aggregate EIS, i.e. $(1-\lambda) \sigma$, appears to be well identified, implying that instruments are weak for labour income growth but stronger for the real interest rate in most countries. In Sweden and Switzerland, $\lambda$ is well identified and turns out to be low, and therefore the admissible values of $\sigma$ are also low and not very different from the ones in the baseline model.

One possible explanation for low values of $\sigma$ in the results discussed so far could be the inability of the models to fit the empirical data due to model misspecification. For instance, the set of countries considered in this paper are all open economies that trade with the rest of the world and so aggregate output possibly also depend on the degree of openness and other open economy features like terms of trade fluctuations. To overcome this shortcoming, we extend the closed economy models to incorporate an external sector as discussed in Section 2. The $90 \% S$ sets in panels $(e)$ show that the degree of openness $\omega$ is completely unidentified in all countries, except for Denmark where $\omega$ turns out to be low. Although higher degree of openness $\omega$ permits higher values of $\sigma$ in some countries, $\sigma$ is mostly limited to values lower than 1 . Only in Norway and New Zealand, the admissible values of $\sigma$ exceed 1 when $\omega$ increases, but this comes at a cost since $\omega$ is completely unidentified. The $90 \% q L L-S$ sets in panels $(m)$ show that sub-sample information is helpful for the identification of $\omega$ in Canada (where $\omega$ turns out to be high and include $\omega=1$ ) and Sweden (where $\omega$ turns out to be low and include $\omega=0$ ), but $\sigma$ remains low in either case. Additionally, the $90 \%$ $q L L-S$ set for the baseline open economy for Switzerland turns out to be empty. Note that the $q L L-S$ test of Magnusson and Mavroeidis (2014) serves as a parameter stability test that is fully robust to weak instruments, and therefore this finding provides evidence of structural change in the baseline open economy Euler equation model for Switzerland over our sample period.

We now move to the model that combines the open economy Euler equation model with external and internal habits, in panels $(f)$ and $(g)$ for the $S$ sets, respectively, and panels $(n)$ and $(o)$ for the $q L L-S$ sets. The three-dimensional confidence sets contain a significant part of the parameter space for most countries. As with the closed economy models, both external and internal habits can fit the data with significantly higher values of $\sigma$, but again at the cost of estimation uncertainty since the habit parameter $\gamma$ is not well identified. As with the baseline open economy model without habits, the degree is openness $\omega$ is not properly identified, except for Denmark as before.

The results for the model with HTMC in the open economy are shown in panels $(h)$ and $(p)$ for the $S$ and $q L L-S$ sets, respectively. As with the closed economy model, the fraction of HTMC $\lambda$ remains poorly identified in all countries, except Sweden and Switzerland where $\lambda$ is well identified and low, and $\sigma$ is not significantly different from zero. As before, in the other six countries, high values of $\sigma$ become admissible 
as $\lambda$ increases. In addition, the degree of openness $\omega$ remains poorly identified in most countries, with the exception of Denmark, Sweden and Switzerland, where $\omega$ is low.

Finally, we compare the $q L L-S$ sets in the bottom two panels of each figure with the $S$ sets from the upper two panels, First, we find that by exploiting the information on the validity of the moment conditions over subsamples and thereby using information on time variation in other parts of the open economy, the qLL-S test provides better identification of the structural parameters for Canada, Sweden and Switzerland. This finding is very different from the evidence on the Euler equation for the U.S. economy in Ascari et al. (2019), where the models considered are closed economy variants and they find that the qLL-S sets are bigger than their S counterparts. One possible explanation for this finding is that structural changes arising from the open economy may have had more impact on Canada, Sweden and Switzerland. In contrast, sub-sample information does not seem to provide sufficient additional identification for the rest of the countries. ${ }^{8}$ Second, with the exception of the baseline closed economy model for Canada and Switzerland and the baseline open economy model for Switzerland, we cannot reject the hypothesis that the parameters of the model are stable over the entire sample, as otherwise the $q L L-S$ sets would have been empty.

[Figure 1 about here.]

[Figure 2 about here.]

[Figure 3 about here.]

[Figure 4 about here.]

[Figure 5 about here.]

[Figure 6 about here.]

[Figure 7 about here.]

[Figure 8 about here.]

\section{Conclusion}

This paper investigates the empirical evidence on the Euler equation model using aggregate data for Australia, Canada, Denmark, Norway, New Zealand, Sweden, Switzerland and the United Kingdom. To overcome issues

\footnotetext{
8 In these other countries, the $q L L-S$ sets are still somewhat smaller for some models: open economy internal habits (Australia), baseline open economy and HTM open economy (Norway), baseline closed econonmy (New Zealand). Yet, the reduction in $q L L-S$ sets are not sufficient enough to change the inference qualitatively.
} 
with identification, we use methods that are robust to weak instruments, parameter instability and structural changes. Several findings arise. First, we find that the baseline Euler equation model results in low values of the EIS for all countries, which is in line with the existing empirical literature. Second, extending the baseline model to allow for habits or HTMC provides little improvement. Higher degree of habits allows for higher values of the EIS, but the habit parameter remains completely unidentified. In models with HTMC, the fraction of HTMC is poorly identified in most countries with higher fraction of HTMC admitting higher values of the EIS. We find that exploiting sub-sample information improves identification in some countries. Nevertheless, the EIS turns out to be lower than 1 in most countries, except for models with habits or HTMC which allow for higher values of the EIS, but at the cost of estimation uncertainty of the degree of habits or the fraction of HTMC. The tests also suggest that we cannot reject the hypothesis that the parameters of the model are stable over the entire sample. Hence, analogous to the conclusion reached by Ascari et al. (2019) for the United States, we find that aggregate macro data are not very useful for the study of Euler equation models for the countries in our dataset. 


\section{References}

Ascari, G., L. M. Magnusson, and S. Mavroeidis (2019). Empirical evidence on the Euler equation for consumption in the US. Journal of Monetary Economics (In Press) .

Bilbiie, F. O. (2008). Limited asset markets participation, monetary policy and (inverted) aggregate demand logic. Journal of Economic Theory 140(1), 162-196.

Bilbiie, F. O. and R. Straub (2012). Changes in the output Euler equation and asset markets participation. Journal of Economic Dynamics and Control 36(11), 1659-1672.

Boerma, J. (2014). Openness and the (inverted) aggregate demand logic. De Nederlandsche Bank Working Paper No. 436.

Campbell, J. Y. and N. G. Mankiw (1989). Consumption, Income and Interest Rates: Reinterpreting the Time Series Evidence. In O. J. Blanchard and S. Fischer (Eds.), NBER Macroeconomics Annual 1989, Vol. 4, pp. 185-246. MIT Press.

Christiano, L. J., M. Eichenbaum, and C. L. Evans (2005). Nominal rigidities and the dynamic effects of a shock to monetary policy. Journal of Political Economy 113(1), 1-45.

Clarida, R., J. Galı, and M. Gertler (1999). The science of monetary policy: a New Keynesian perspective. Journal of Economic Literature 37(4), 1661-1707.

Clarida, R., J. Galı, and M. Gertler (2002). A simple framework for international monetary policy analysis. Journal of Monetary Economics 49(5), 879-904.

Dennis, R. (2009). Consumption habits in a New Keynesian business cycle model. Journal of Money, Credit and Banking 41(5), 1015-1030.

Elliott, G. and U. K. Müller (2006). Efficient tests for general persistent time variation in regression coefficients. Review of Economic Studies 73(4), 907-940.

Fuhrer, J. C. (2000). Habit formation in consumption and its implications for monetary-policy models. American Economic Review 90(3), 367-390.

Fuhrer, J. C. and G. D. Rudebusch (2004). Estimating the Euler equation for output. Journal of Monetary Economics 51(6), 1133-1153.

Galí, J. (2008). Monetary Policy, Inflation, and the Business Cycle. Princeton University Press, Princeton. 
Galí, J. and T. Monacelli (2005). Monetary policy and exchange rate volatility in a small open economy. Review of Economic Studies 72(3), 707-734.

Gomes, F. A. R. and L. S. Paz (2013). Estimating the elasticity of intertemporal substitution: is the aggregate financial return free from the weak instrument problem? Journal of Macroeconomics 36, 63-75.

Goodfriend, M. and R. G. King (1997). The new neoclassical synthesis and the role of monetary policy. NBER macroeconomics annual 12, 231-283.

Goodhart, C. A. E. and B. Hofmann (2003). The IS curve and the transmission of monetary policy: is there a puzzle? ZEI Working Paper No. B13-2003.

Hall, R. E. (1988). Intertemporal substitution in consumption. Journal of political economy 96(2), 339-357.

Hansen, L. P., J. Heaton, and A. Yaron (1996). Finite-sample properties of some alternative GMM estimators. Journal of Business 83 Economic Statistics 14(3), 262-280.

Hansen, L. P. and K. J. Singleton (1982). Generalized instrumental variables estimation of nonlinear rational expectations models. Econometrica 50(5), 1269-1286.

Havránek, T. (2015). Measuring intertemporal substitution: The importance of method choices and selective reporting. Journal of the European Economic Association 13(6), 1180-1204.

Kleibergen, F. (2005). Testing parameters in gmm without assuming that they are identified. Econometrica 73(4), 1103-1123.

Magnusson, L. M. and S. Mavroeidis (2014). Identification using stability restrictions. Econometrica 82(5), $1799-1851$.

Moreira, M. J. (2003). A conditional likelihood ratio test for structural models. Econometrica 71(4), $1027-1048$.

Newey, W. K. and K. D. West (1987). A simple, positive semidefinite, heteroskedasticity and autocorrelation consistent covariance matrix. Econometrica 55(3), 703-708.

Olea, J. L. M. and C. Pflueger (2013). A robust test for weak instruments. Journal of Business \& Economic Statistics 31(3), 358-369.

Paradiso, A., S. Kumar, and B. B. Rao (2013). A New Keynesian IS curve for Australia: is it forward looking or backward looking? Applied Economics 45(26), 3691-3700. 
Patterson, K. D. and B. Pesaran (1992). The intertemporal elasticity of substitution in consumption in the United States and the United Kingdom. Review of Economics and Statistics 74(4), 573-584.

Smets, F. and R. Wouters (2007). Shocks and frictions in US business cycles: a bayesian DSGE approach. American Economic Review 97(3), 586-606.

Stock, J. H. and J. H. Wright (2000). GMM with weak identification. Econometrica 68(5), 1055-1096.

Stock, J. H., J. H. Wright, and M. Yogo (2002). A survey of weak instruments and weak identification in generalised method of moments. Journal of Business 8 Economic Statistics 20(4), 518-529.

Stracca, L. (2010). Is the New Keynesian IS curve structural? ECB Working Paper No. 1236.

Woodford, M. (2003). Interest and Prices: Foundations of a Theory of Monetary Policy. Princeton University Press, Princeton.

Yogo, M. (2004). Estimating the elasticity of intertemporal substitution when instruments are weak. Review of Economics and Statistics 86(3), 797-810. 


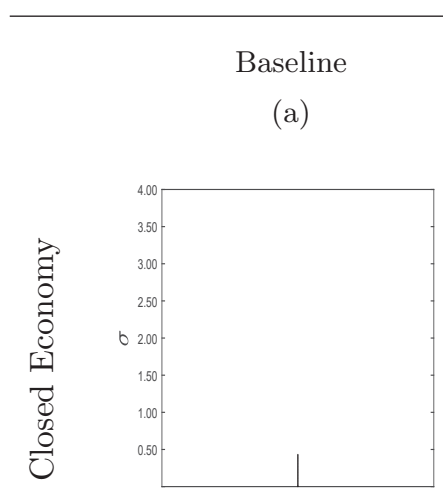

(e)

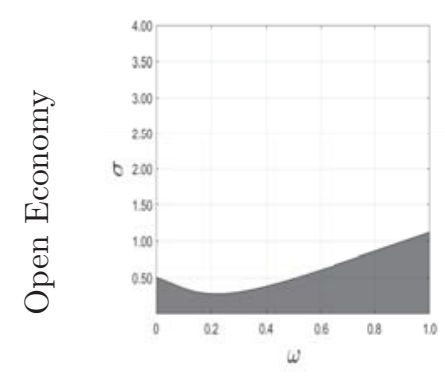

External Habits

(b)

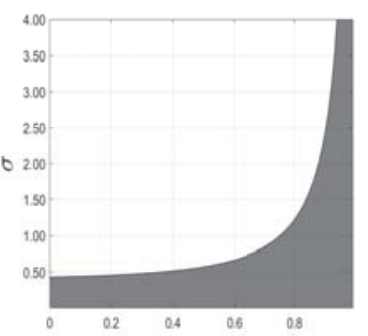

(f)

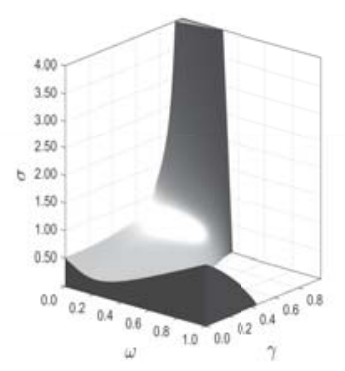

Internal Habits

(c)

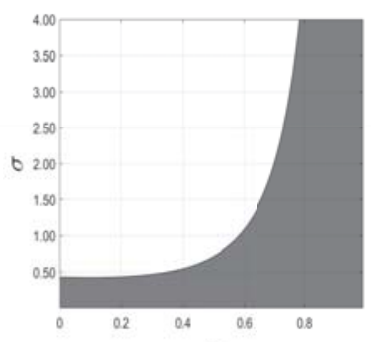

$(\mathrm{g})^{?}$

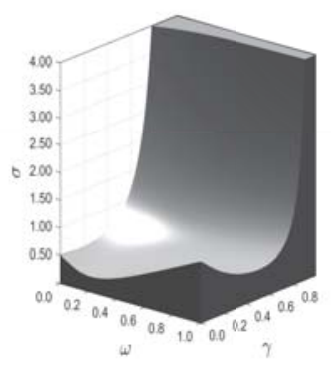

HTM

(d)

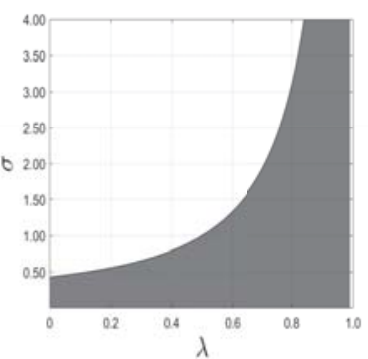

(h)

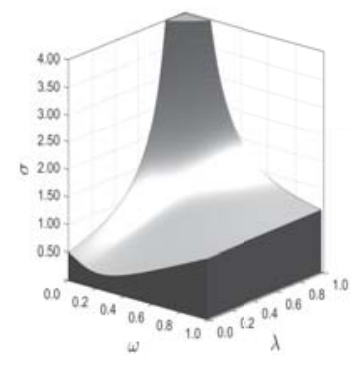

Panel B: qLL-S confidence sets

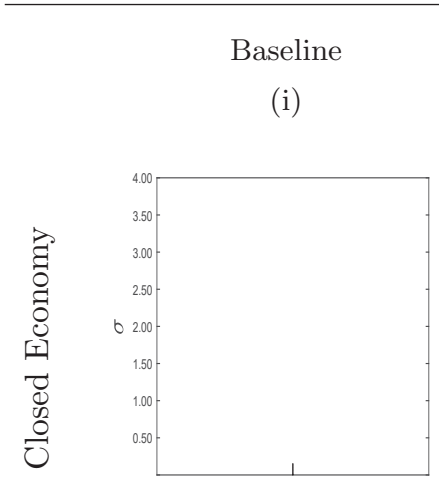

(m)

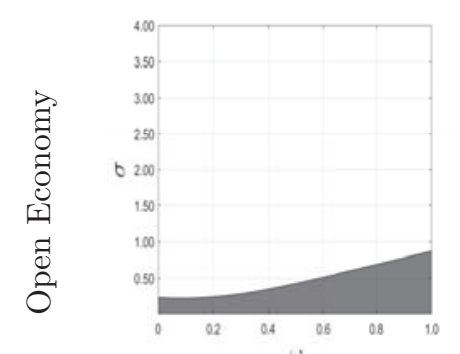

External Habits

(j)

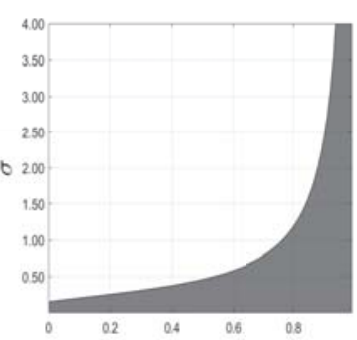

$(n)^{\gamma}$

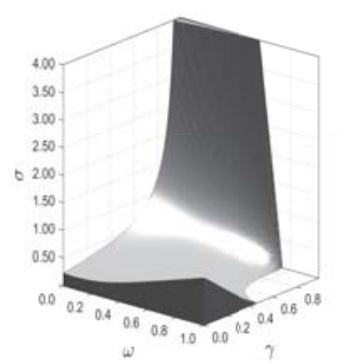

Internal Habits

(k)

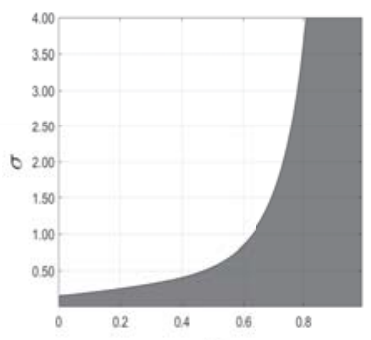

$(\mathrm{o})^{\gamma}$

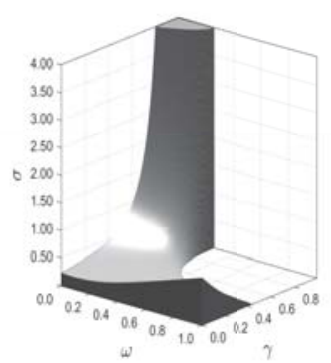

HTM

(l)

(p)

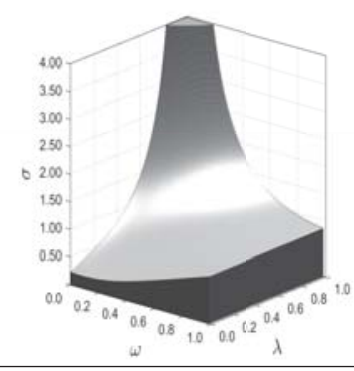

Figure 1: Australia: 90\% confidence sets for S test (top two panels) and qLL-S test (bottom two panels) for $\sigma, \gamma, \lambda$ and $\omega$ in the log-linear models. Instruments: constant, the second lag of $\Delta y_{t},\left(i_{t-1}-\pi_{t}\right)$ and $\left(i_{t-1}^{*}-\pi_{t}^{*}\right)$. For open economy models, we also include the second lag of $\Delta s_{t} . \eta=1, \beta=0.99$. Newey and West (1987) HAC with 4 lags. Period: 1968q1-2018q4. 


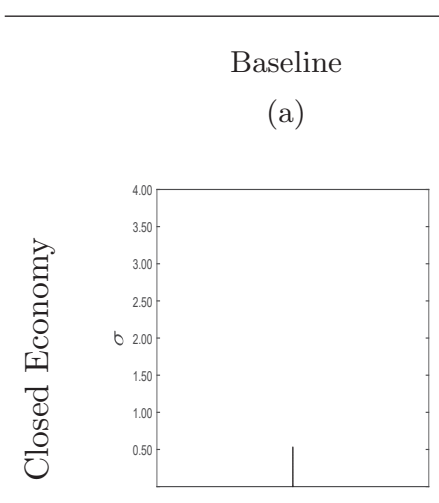

(e)
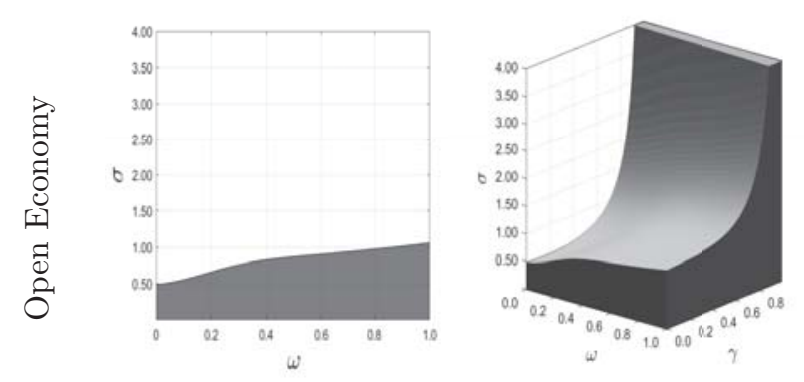

Internal Habits

(c)

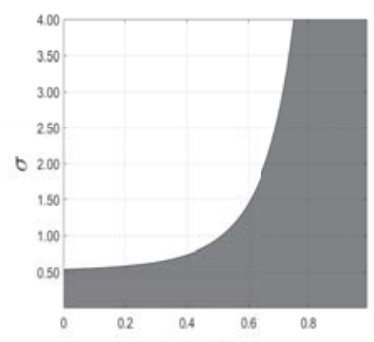

$(\mathrm{g})^{?}$

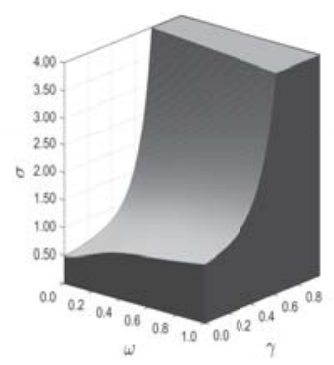

HTM

(d)

Panel B: qLL-S confidence sets

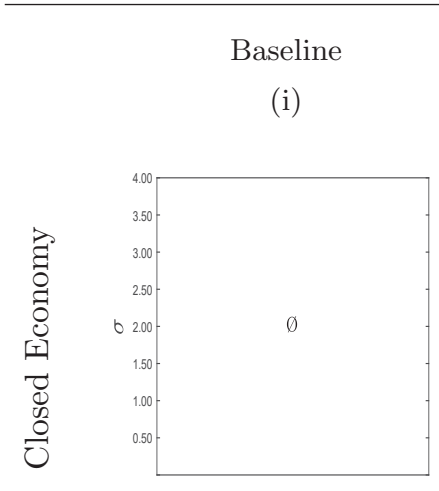

(m)

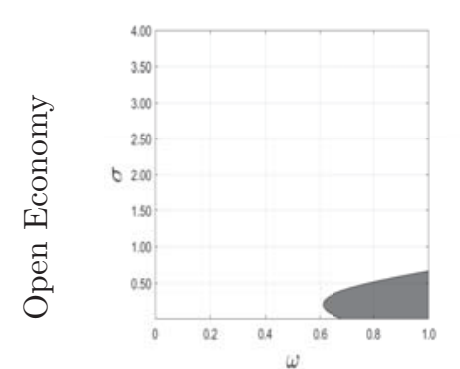

External Habits

(j)

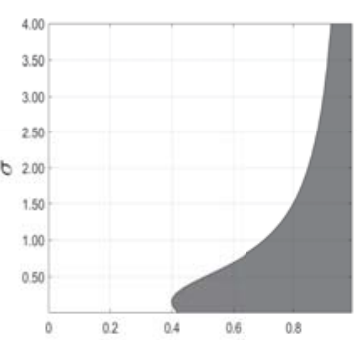

$(\mathrm{n})^{\gamma}$

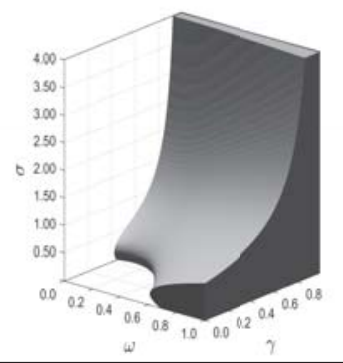

Internal Habits

(k)

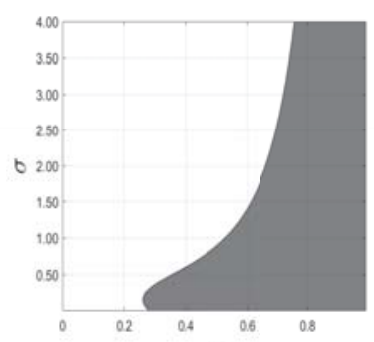

$(\mathrm{o})^{\gamma}$

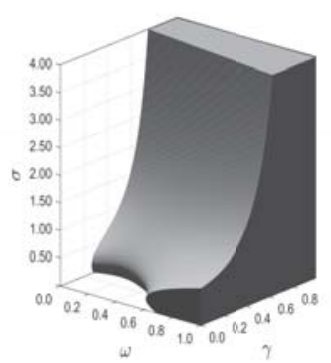

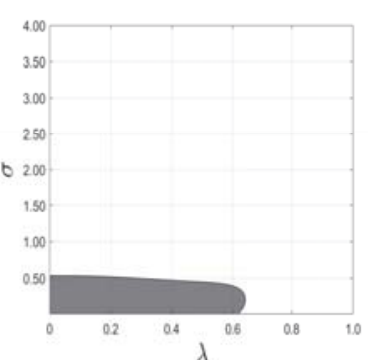

(h)

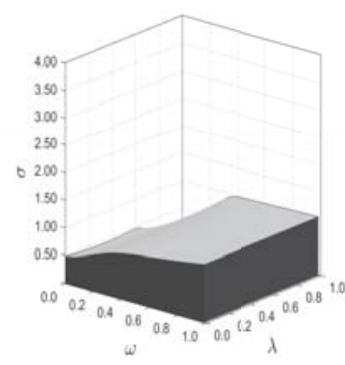

Figure 2: Canada: $90 \%$ confidence sets for $\mathrm{S}$ test (top two panels) and qLL-S test (bottom two panels) for $\sigma, \gamma, \lambda$ and $\omega$ in the log-linear models. Instruments: constant, the second lag of $\Delta y_{t},\left(i_{t-1}-\pi_{t}\right)$ and $\left(i_{t-1}^{*}-\pi_{t}^{*}\right)$. For open economy models, we also include the second lag of $\Delta s_{t} . \eta=1, \beta=0.99$. Newey and West (1987) HAC with 4 lags. Period: 1961q1-2018q4. 


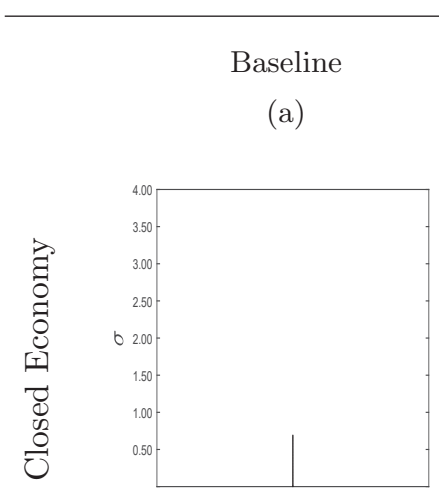

(e)

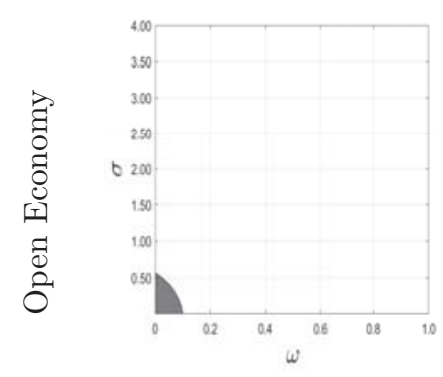

External Habits

(b)

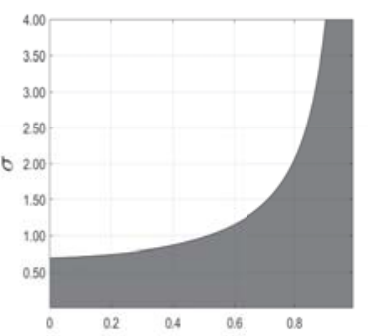

(f)

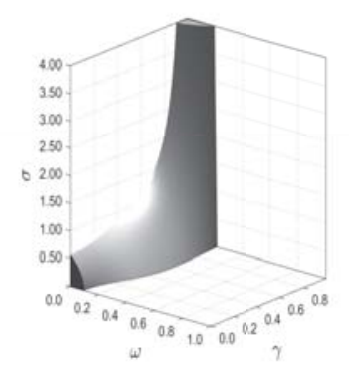

Internal Habits

(c)

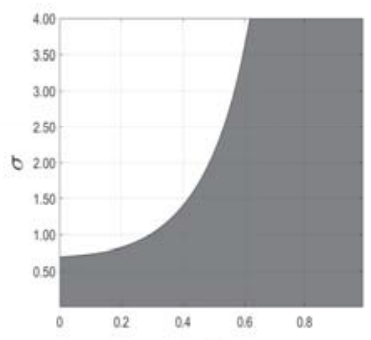

$(\mathrm{g})^{?}$

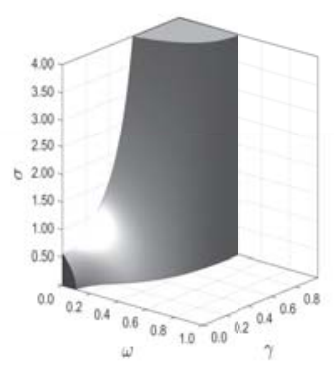

HTM

(d)

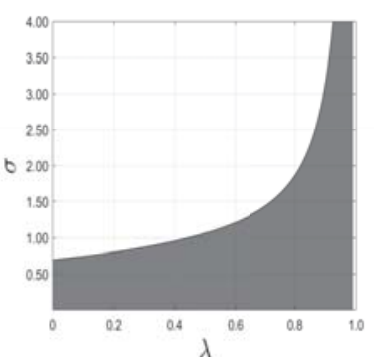

(h)

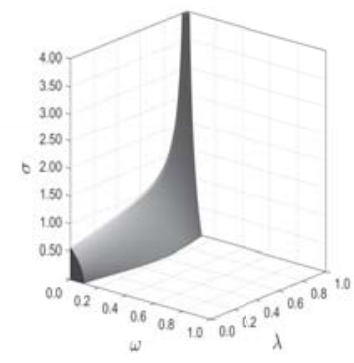

Panel B: qLL-S confidence sets

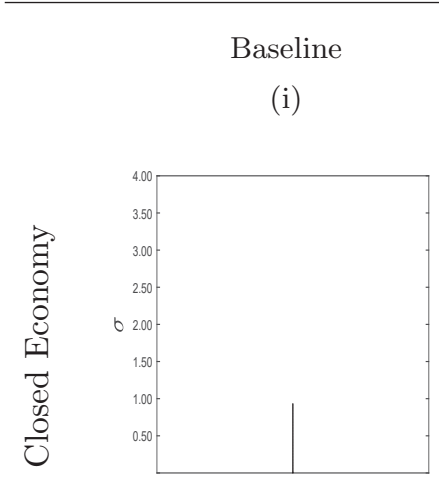

(m)

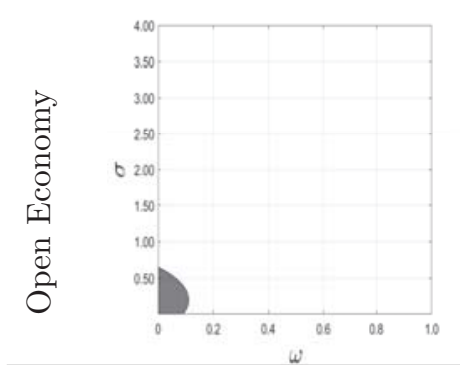

External Habits

(j)

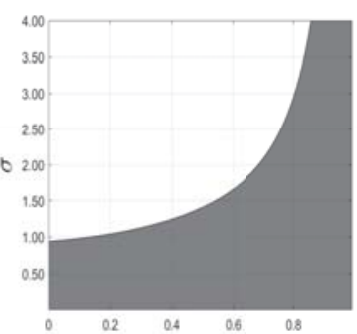

$(\mathrm{n})^{\gamma}$

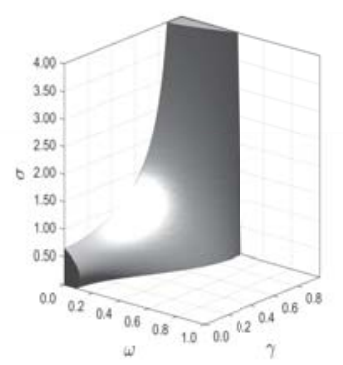

Internal Habits

(k)

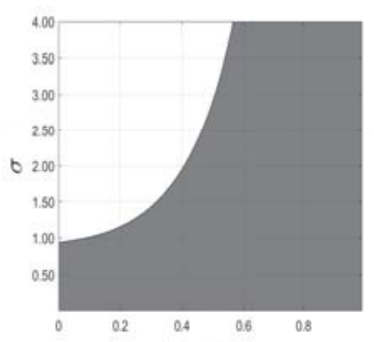

(o)

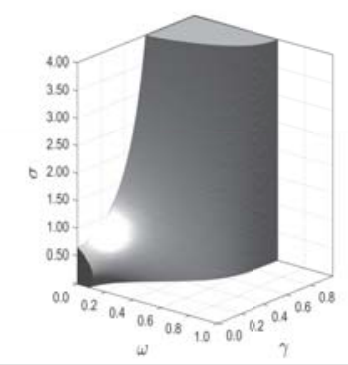

HTM

(l)

(p)

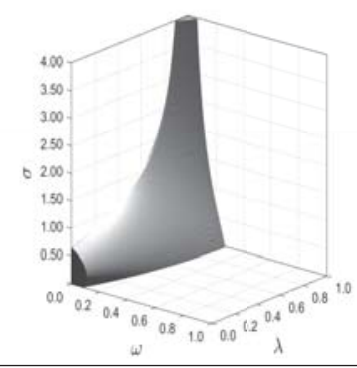

Figure 3: Denmark: 90\% confidence sets for S test (top two panels) and qLL-S test (bottom two panels) for $\sigma, \gamma, \lambda$ and $\omega$ in the log-linear models. Instruments: constant, the second lag of $\Delta y_{t},\left(i_{t-1}-\pi_{t}\right)$ and $\left(i_{t-1}^{*}-\pi_{t}^{*}\right)$. For open economy models, we also include the second lag of $\Delta s_{t} . \eta=1, \beta=0.99$. Newey and West (1987) HAC with 4 lags. Period: 1995q1-2018q4. 


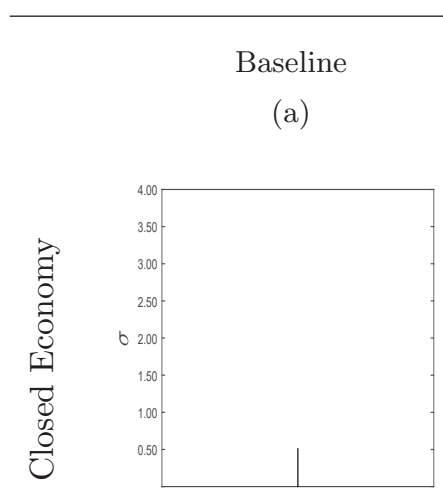

(e)

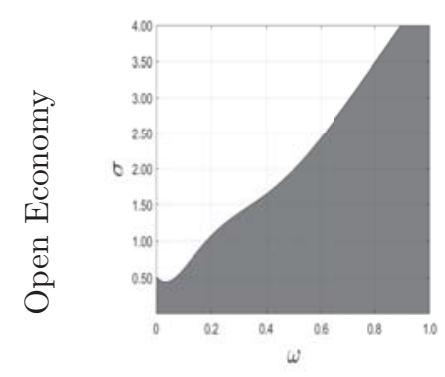

External Habits

(b)

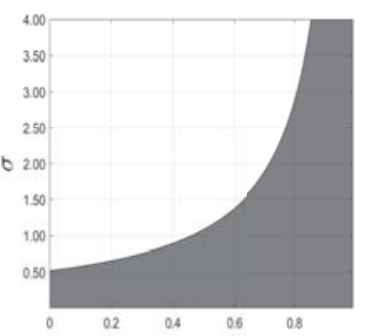

(f)

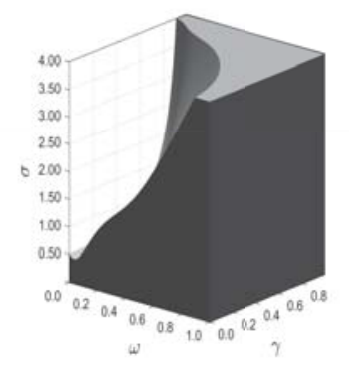

Internal Habits

(c)

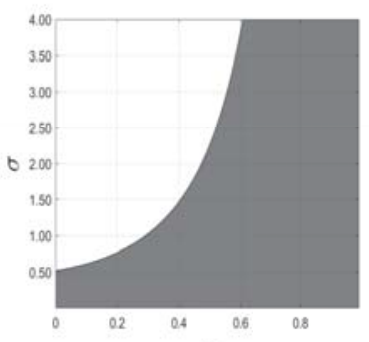

$(\mathrm{g})^{\gamma}$

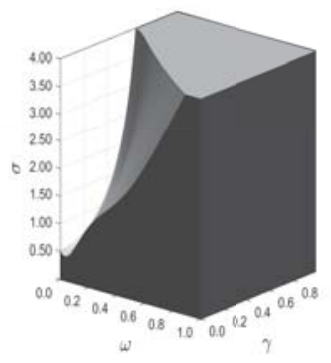

HTM

(d)

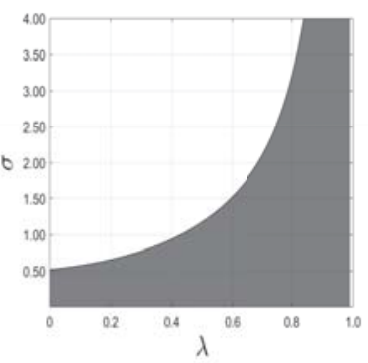

(h)

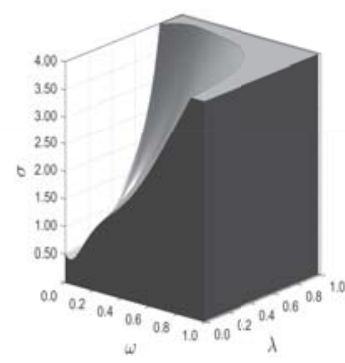

Panel B: qLL-S confidence sets

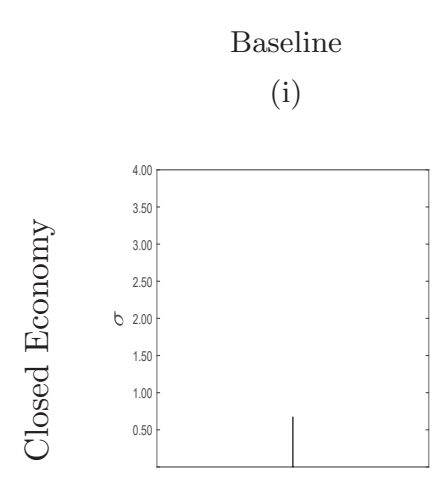

(m)

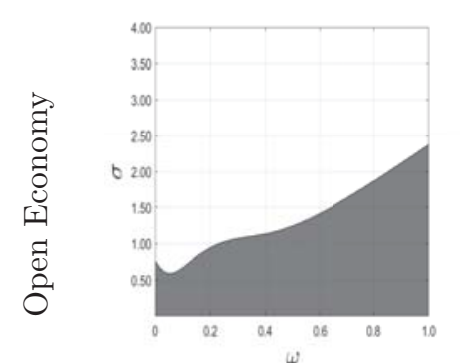

External Habits

(j)

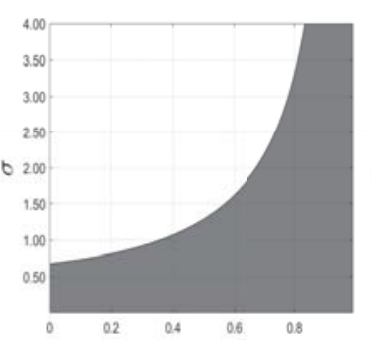

$(\mathrm{n})^{\gamma}$

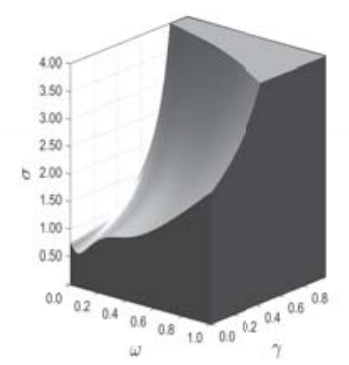

Internal Habits

(k)

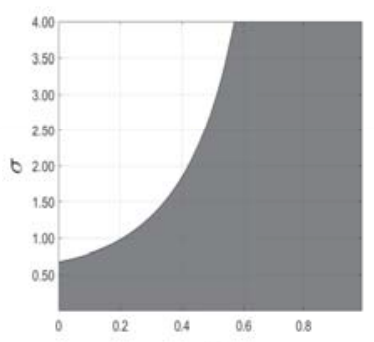

(o)

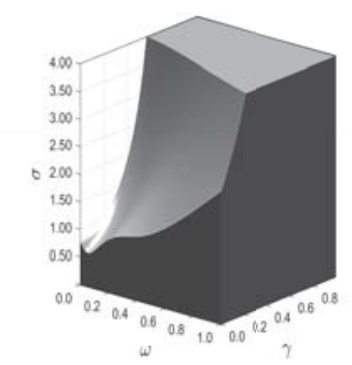

HTM

(l)

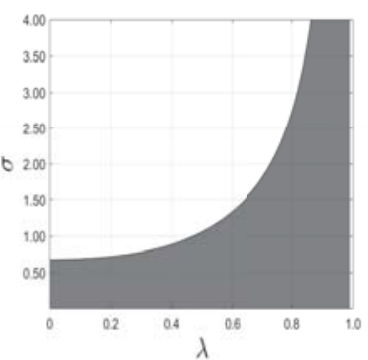

(p)

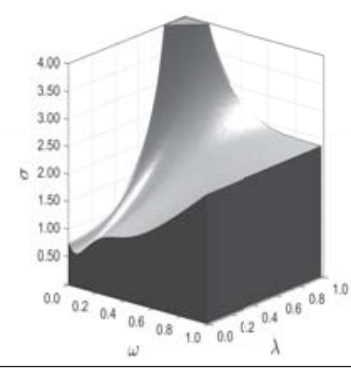

Figure 4: Norway: 90\% confidence sets for S test (top two panels) and qLL-S test (bottom two panels) for $\sigma, \gamma, \lambda$ and $\omega$ in the log-linear models. Instruments: constant, the second lag of $\Delta y_{t},\left(i_{t-1}-\pi_{t}\right)$ and $\left(i_{t-1}^{*}-\pi_{t}^{*}\right)$. For open economy models, we also include the second lag of $\Delta s_{t} . \eta=1, \beta=0.99$. Newey and West (1987) HAC with 4 lags. Period: 1995q1-2018q4. 


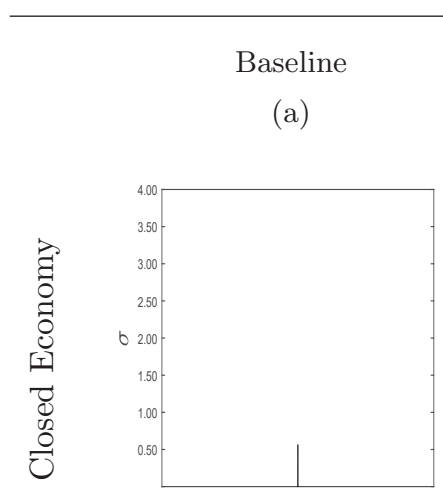

(e)

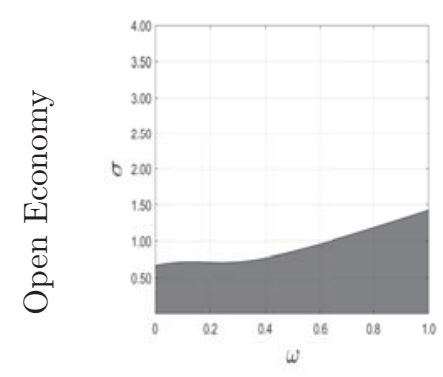

External Habits

(b)

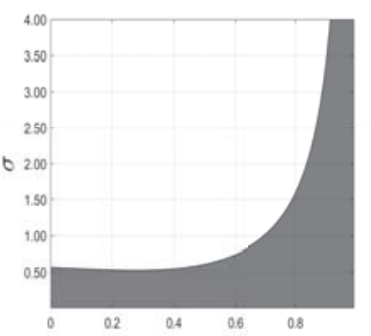

(f)

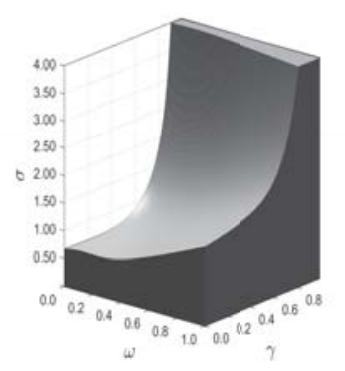

Internal Habits

(c)

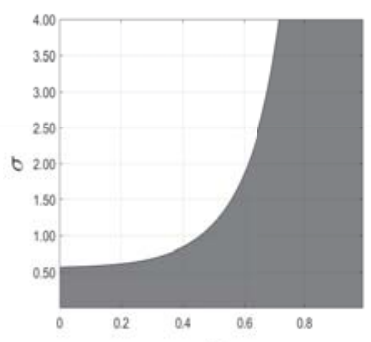

$(\mathrm{g})^{?}$

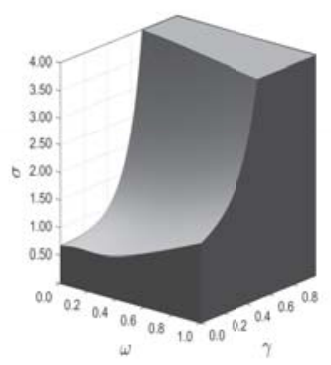

HTM

(d)

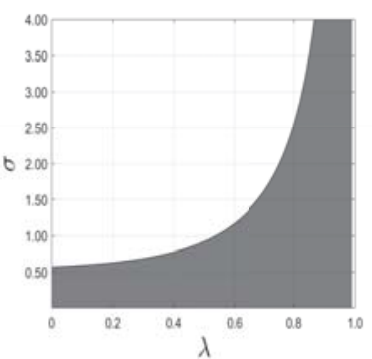

(h)

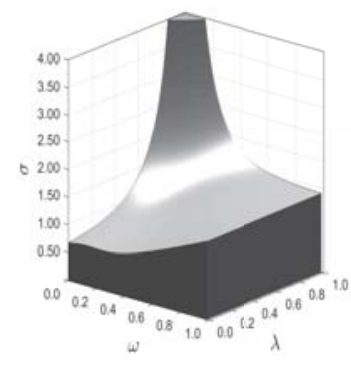

Panel B: qLL-S confidence sets

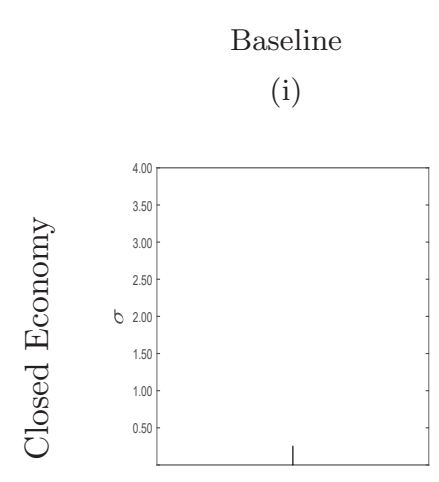

(m)

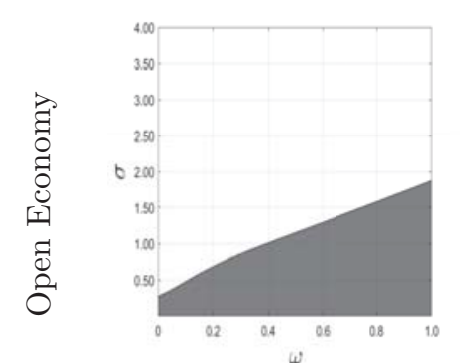

External Habits

(j)

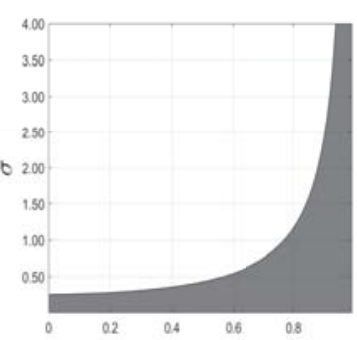

$(n)^{\gamma}$

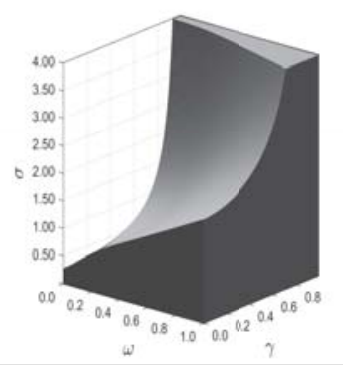

Internal Habits

(k)

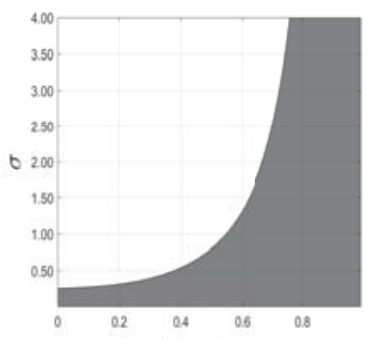

$(\mathrm{o})^{\gamma}$

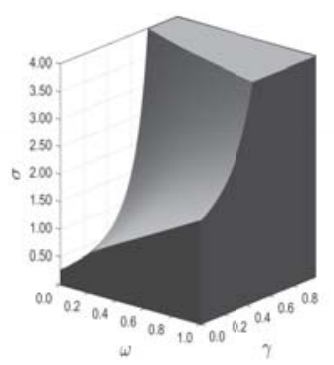

HTM

(l)

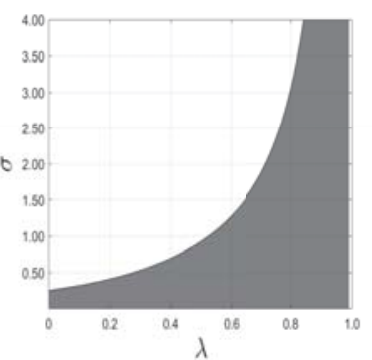

(p)

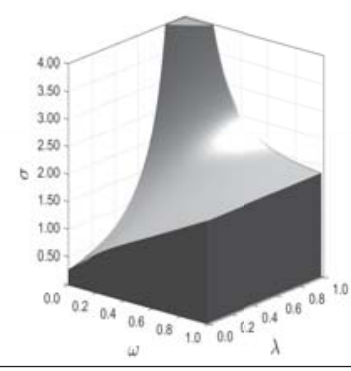

Figure 5: New Zealand: $90 \%$ confidence sets for S test (top two panels) and qLL-S test (bottom two panels) for $\sigma, \gamma, \lambda$ and $\omega$ in the log-linear models. Instruments: constant, the second lag of $\Delta y_{t},\left(i_{t-1}-\pi_{t}\right)$ and $\left(i_{t-1}^{*}-\pi_{t}^{*}\right)$. For open economy models, we also include the second lag of $\Delta s_{t} . \eta=1, \beta=0.99$. Newey and West (1987) HAC with 4 lags. Period: 1989q1-2018q4. 


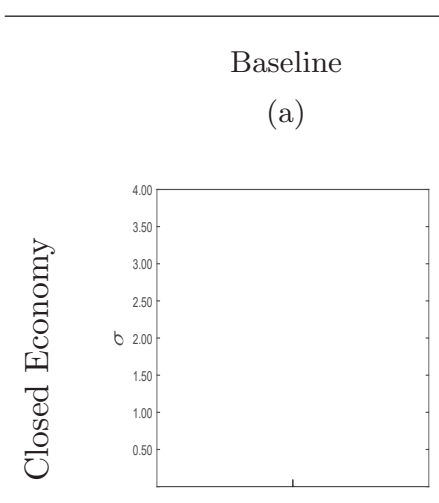

(e)

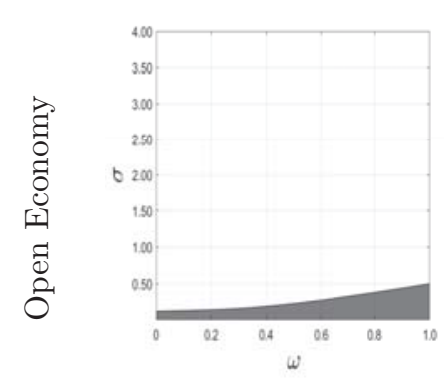

Internal Habits

(c)

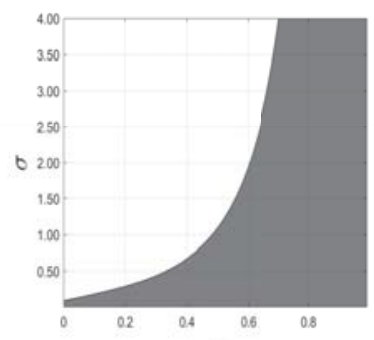

(g)

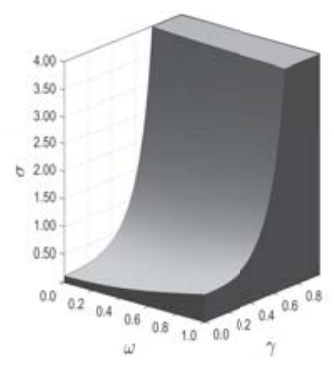

HTM

(d)

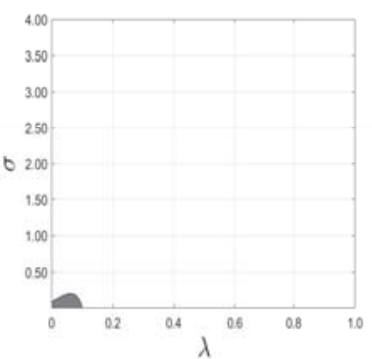

(h)

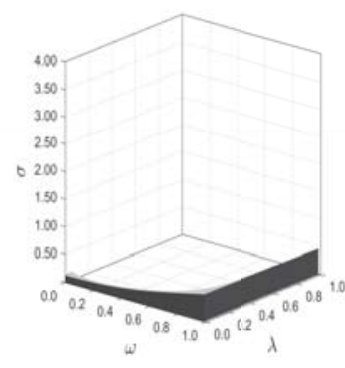

Panel B: qLL-S confidence sets

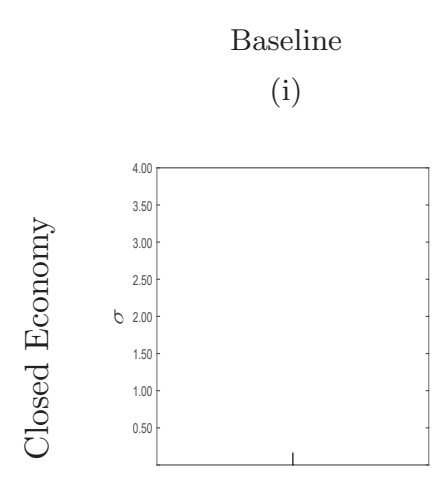

(m)

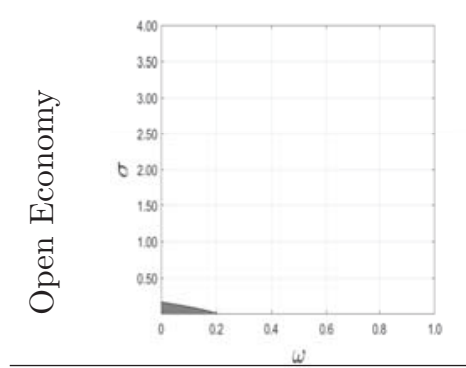

External Habits

(j)

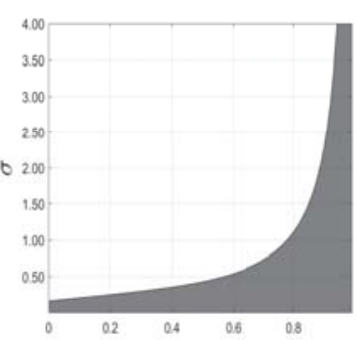

$(n)^{\gamma}$

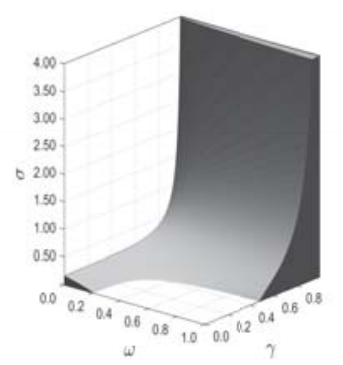

Internal Habits

(k)

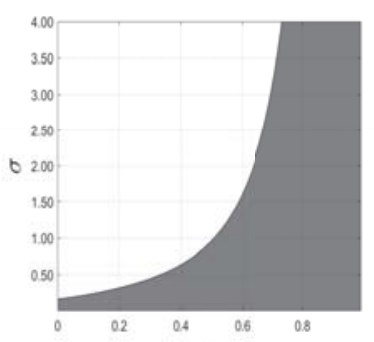

(o)

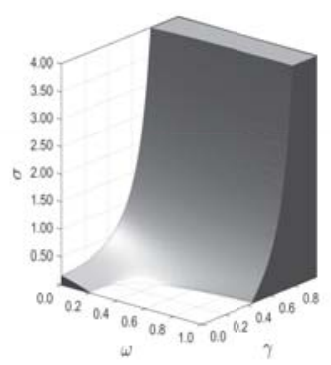

HTM

(l)

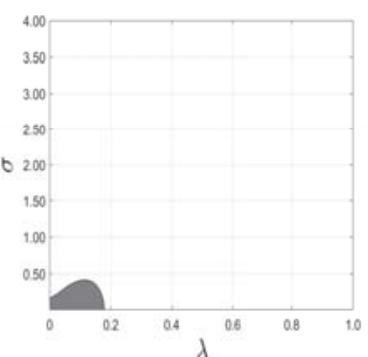

(p)

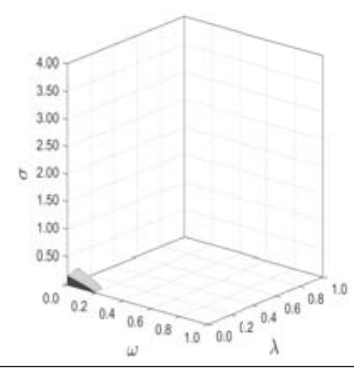

Figure 6: Sweden: $90 \%$ confidence sets for $\mathrm{S}$ test (top two panels) and qLL-S test (bottom two panels) for $\sigma, \gamma, \lambda$ and $\omega$ in the log-linear models. Instruments: constant, the second lag of $\Delta y_{t},\left(i_{t-1}-\pi_{t}\right)$ and $\left(i_{t-1}^{*}-\pi_{t}^{*}\right)$. For open economy models, we also include the second lag of $\Delta s_{t} . \eta=1, \beta=0.99$. Newey and West (1987) HAC with 4 lags. Period: 1980q1-2018q4. 


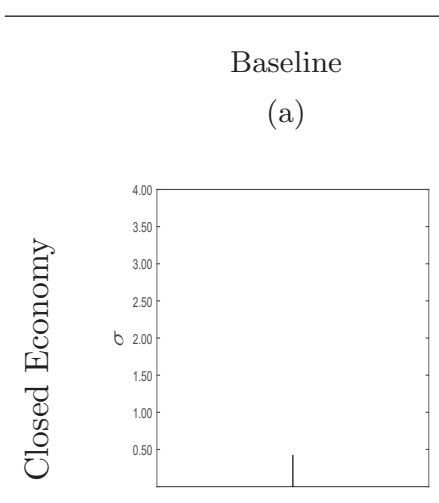

(e)

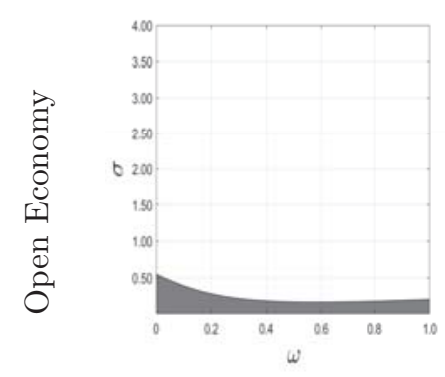

External Habits

(b)

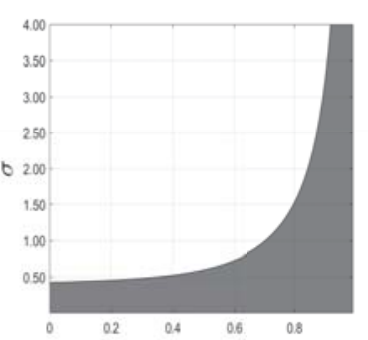

(f)

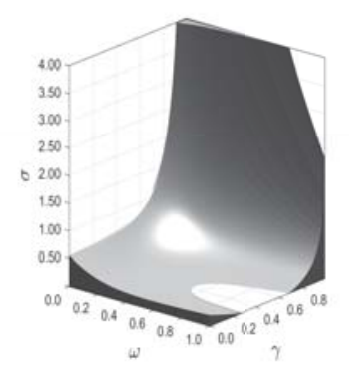

Internal Habits

(c)

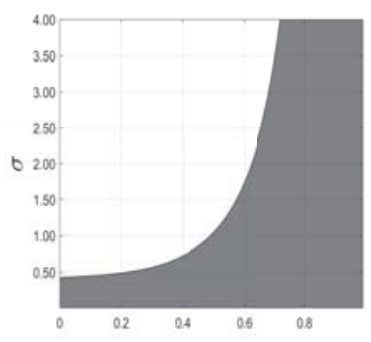

$(\mathrm{g})^{?}$

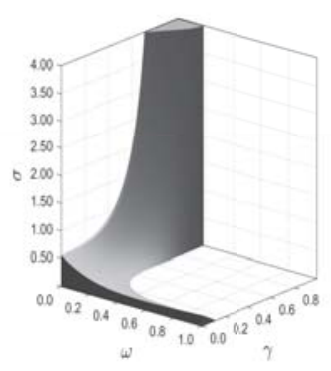

HTM

(d)

Panel B: qLL-S confidence sets

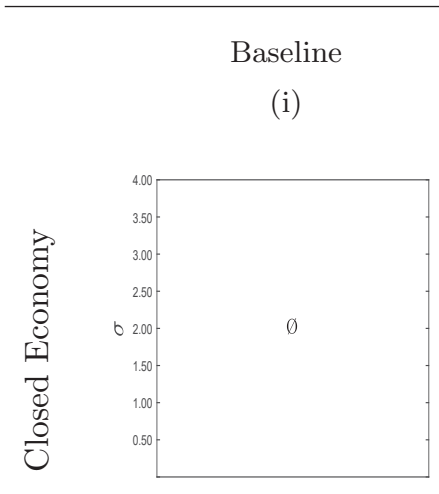

(m)

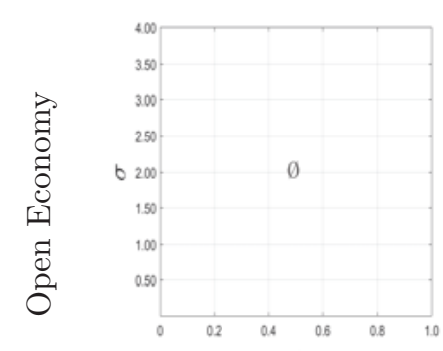

External Habits

(j)

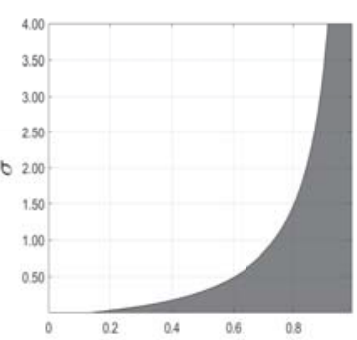

$(\mathrm{n})^{\gamma}$

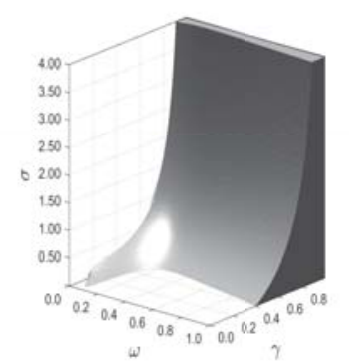

Internal Habits

(k)

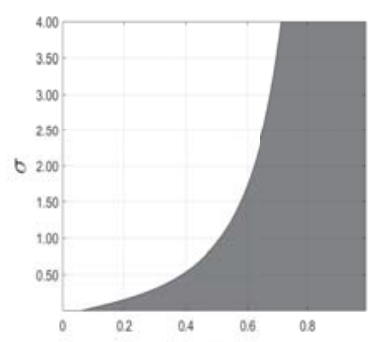

(o)

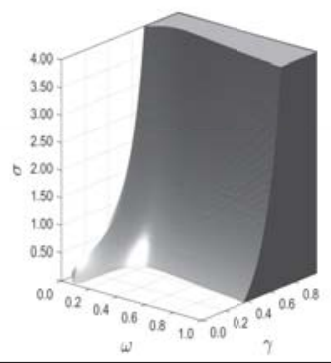

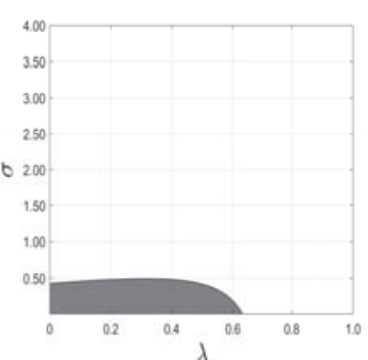

(h)

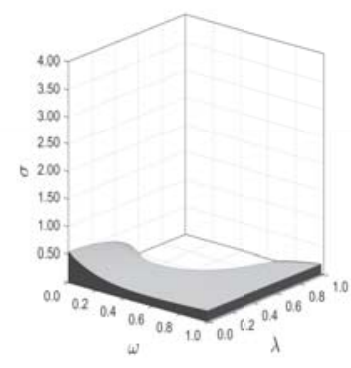

HTM

(l)

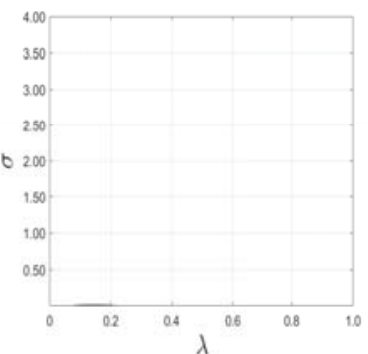

(p)

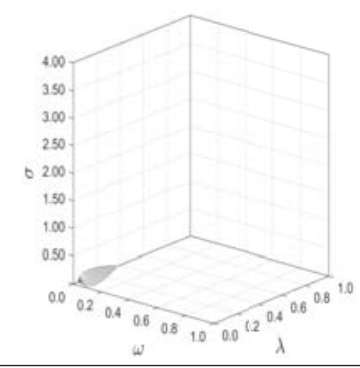

Figure 7: Switzerland: $90 \%$ confidence sets for S test (top two panels) and qLL-S test (bottom two panels) for $\sigma, \gamma, \lambda$ and $\omega$ in the log-linear models. Instruments: constant, the second lag of $\Delta y_{t},\left(i_{t-1}-\pi_{t}\right)$ and $\left(i_{t-1}^{*}-\pi_{t}^{*}\right)$. For open economy models, we also include the second lag of $\Delta s_{t} . \eta=1, \beta=0.99$. Newey and West (1987) HAC with 4 lags. Period: 1990q1-2018q4. 


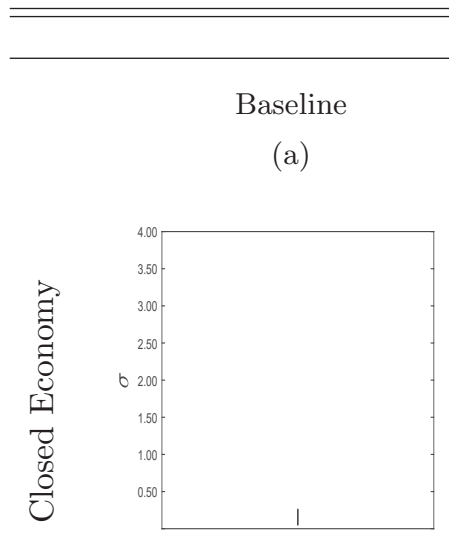

(e)
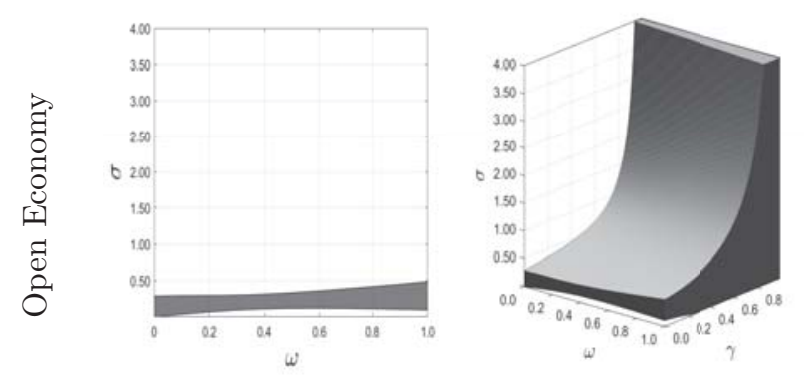

Internal Habits

(c)

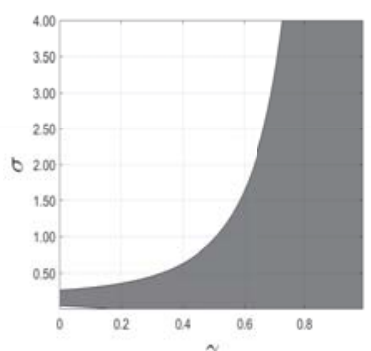

(g)

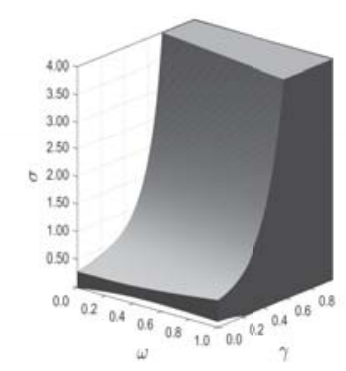

HTM

(d)

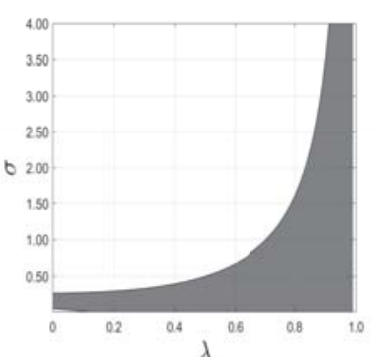

(h)

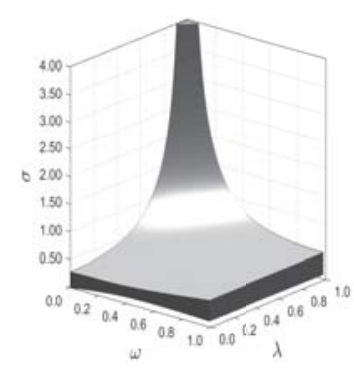

Panel B: qLL-S confidence sets

Baseline

(i)

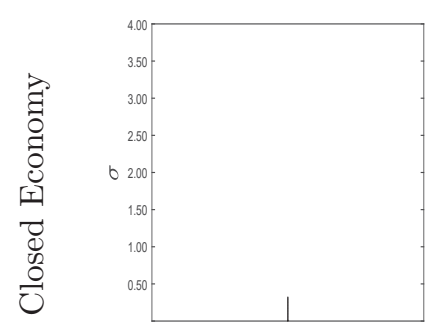

(m)

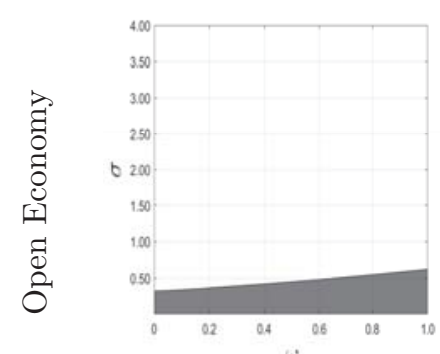

Internal Habits

(k)

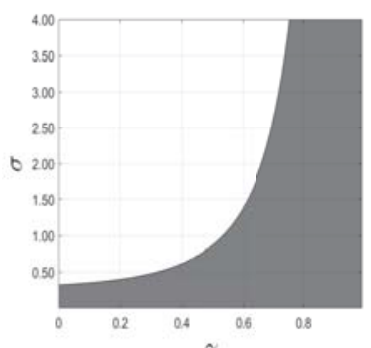

(o)

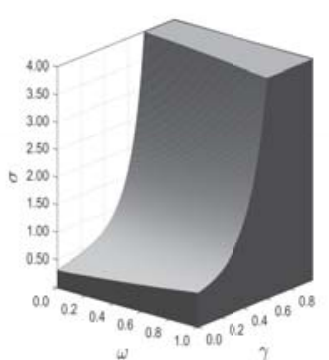

HTM

(1)

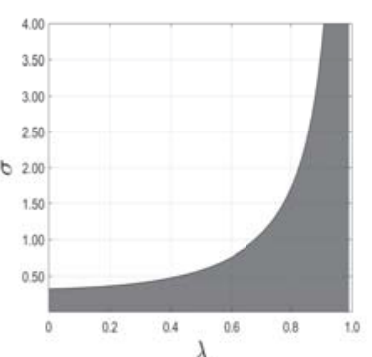

(p)

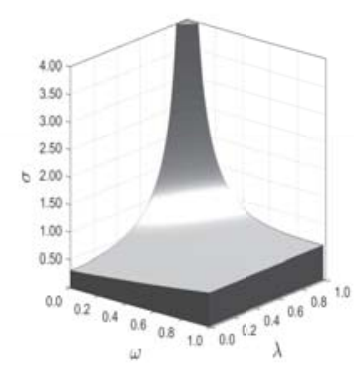

Figure 8: United Kingdom: $90 \%$ confidence sets for $\mathrm{S}$ test (top two panels) and qLL-S test (bottom two panels) for $\sigma$, $\gamma, \lambda$ and $\omega$ in the log-linear models. Instruments: constant, the second lag of $\Delta y_{t},\left(i_{t-1}-\pi_{t}\right)$ and $\left(i_{t-1}^{*}-\pi_{t}^{*}\right)$. For open economy models, we also include the second lag of $\Delta s_{t} \cdot \eta=1, \beta=0.99$. Newey and West (1987) HAC with 4 lags. Period: 1963q1-2018q4. 